\title{
Investigating the effect of transient flow behavior from HSW to LSW on oil recovery in low-salinity water flooding simulation
}

\author{
Sajjad Esmaeili ${ }^{1}$ (D) Sepideh Maaref ${ }^{1}$
}

Received: 16 April 2018 / Accepted: 5 October 2018 / Published online: 17 October 2018

(c) The Author(s) 2018

\begin{abstract}
Low-salinity water (LSW) flooding is one of the newest EOR techniques which has more advantageous over other EOR techniques. This research employed a heterogeneous synthetic three-dimensional reservoir to model LSW flooding for a two-phase system including brine (high salinity to low salinity) and oil. The obtained results show that exact determination of salinity threshold and its wettability alteration coefficients are very important since they affect the maximum value of oil recovery. The oil recovery has been varied between 55.79 and $60.34 \%$ for a given injection brine salinity (500 ppm) at different salinity threshold values. Furthermore, the result reveals that aging time has a low effect on oil recovery which is around $0.066 \%$ after more than 12 years of injection. However, the fine-grid 1D simulation of a small sample demonstrates that the aging time effect should be considered in small-scale models. Furthermore, we prove that there is an optimum value of injection brine salinity for each reservoir according to its salinity threshold. Highest recovery changes occur at the salinity of 5000, 3400 and $1200 \mathrm{ppm}$ for three different salinity thresholds approximately. This paper demonstrates that before any implementation of LSW flooding, many laboratory tests must be done at reservoir condition to precisely detect wettability alteration coefficient, the best injection brine salinity and flow behavior from high-salinity water to LSW.
\end{abstract}

Keywords Enhanced oil recovery $\cdot$ Wettability alteration $\cdot$ Low-salinity water flooding $\cdot$ Salinity threshold $\cdot$ Aging time

\section{List of symbols}

$k_{r w} \quad$ Relative permeability to water

$k_{r o} \quad$ Relative permeability to oil

$S_{o} \quad$ Oil saturation

$S_{w} \quad$ Water saturation

$S_{\text {orw }} \quad$ Residual oil saturation

$S_{w r} \quad$ Residual water saturation

$k_{z} \quad$ Permeability of grid block in vertical direction

$C_{m} \quad$ Salt concentration of each block

$c_{\mathrm{b}} \quad$ Brine compressibility

$k_{\mathrm{rw}}^{\mathrm{LSW}} \quad$ Low-salinity water relative permeability

$k_{\mathrm{ro}}^{\mathrm{HSW}} \quad$ High-salinity oil relative permeability

$P_{\mathrm{c}}^{\mathrm{LS}} \quad$ Low-salinity capillary pressure

$F_{1} \quad$ Weighting coefficient $k_{x}, k_{y}$

$T \quad$ Reservoir temperature

$p_{0} \quad$ Reference pressure (70 MPa)

$P_{\mathrm{c}} \quad$ Capillary pressure

$k_{\mathrm{rw}}^{\mathrm{HSW}} \quad$ High-salinity water relative permeability

$k_{\mathrm{ro}}^{\mathrm{LW}} \quad$ Low-salinity oil relative permeability

$P_{\mathrm{c}}^{\mathrm{HSW}} \quad$ High-salinity capillary pressure

\section{Greek symbols}

$\varphi \quad$ Porosity of each block

$\mu_{\mathrm{w}} \quad$ Water viscosity

$\rho_{\mathrm{b}}^{\mathrm{st}} \quad$ Brine density at standard condition

$\mu_{\mathrm{w}}^{0}\left(20^{\circ} \mathrm{C}\right) \quad$ Water viscosity at temperature of $20^{\circ} \mathrm{C}$ and zero pressure

$\rho_{\mathrm{w} 0} \quad$ Pure water density at reference pressure

$\rho_{\mathrm{b} 0} \quad$ Brine density at reference pressure

$\rho_{\mathrm{b}} \quad$ Brine density

\section{Abbreviations}

EOR Enhanced oil recovery

HSW High-salinity water

MIE Multiple ion exchange

1D One dimensional

EDL Electrical double layer

Department of Chemical and Petroleum Engineering,

University of Calgary, Calgary, Canada

Sajjad.Esmaeili1@ucalgary.ca

Sepideh Maaref

Sepideh.Maaref@ucalgary.ca 
LSW Low-salinity water

PV Pore volume

\section{Introduction}

Recently, laboratory tests and field applications have shown that low-salinity water (LSW) injection is one of the valuable EOR methods in terms of its advantageous in chemical cost, environmental impact and field-scale implementation compared to conventional chemical EOR methods (Dang et al. 2013; Zeinijahromi et al. 2015). The first signs of prospective oil recovery improvement during LSW flooding are corresponding to a study carried out by Reiter (1961), when he found an increase in oil production rate within water injection at different salinities. Later on, Bernard (1967) examined the relative effectiveness of fresh water and salty water during water flooding and demonstrated that oil recovery has increased when water salinity reduced from 15,000 to $100 \mathrm{ppm}$. Tang and Morrow (1997) also investigated the benefit of brine salinity reduction on oil recovery performance.

In term of low-salinity water injection, extensive numbers of published data have demonstrated that the interplay of many factors, such as crude oil properties, brine salinity, brine composition, rock mineral composition, and reservoir temperature can affect the oil recovery (Purswani et al. 2017). Jadhunandan and Morrow (1995) and Yildiz and Morrow (1996) confirmed that brine composition has an impact on oil recovery in water flooding and it can be changed to optimize water flooding recovery. Austad et al. (2007, 2011), Fathi et al. (2010), Zhang et al. (2006) and Qiao et al. (2014) also suggested that improve oil recovery is not only achieved by low salinity, but also the specific composition of the injection water matters (Qiao et al. 2016). Based on large number of laboratory studies performed on carbonate and sandstone reservoirs, $\mathrm{Mg}^{2+}, \mathrm{Ca}^{2+}$ and $\mathrm{SO}_{4}^{2-}$ ions presenting in seawater were proven to be the potential determining ions responsible for incremental oil recovery during LSW flooding (Bader 2007; Puntervold et al. 2007; Shariatpanahi et al. 2010; Strand et al. 2008; Zhang et al. 2007a).

Tang and Morrow (1999) proposed a theoretical interpretation of the mechanism behind the effect of composition and salinity in LSW flooding. However, experimental core flooding tests conducted by Jerauld et al. (2008) showed that the oil recovery enhancement does not generally depend on salinity below a certain threshold. They reported this threshold salinity to be in the ranges of 1000-7000 ppm. Zhang et al. (2007b) demonstrated that low-salinity concentration of $1500 \mathrm{ppm}$ is required during tertiary oil recovery process. Furthermore, Webb et al. (2005a) realized that by decreasing salinity from 5600 to
$1500 \mathrm{ppm}$, the recovery has slightly increased; Morrow et al. (1998) have also figured out this behavior, but with a different threshold. More investigations have been also taken place regarding this matter (Berg et al. 2010; Mahani et al. 2011; Mohamed et al. 2013; Takahashi and Kovscek 2010; Tang and Morrow 1997; Webb et al. 2008; Zhang and Morrow 2006).

Several field applications of LSW flooding indicated its feasibility at reservoir field scale. Webb et al. (2003) reported a decrease in oil saturation about $25-50 \%$ during LSW flooding based on the log-injection-log tests. In 2005, McGuire et al. (2005) expressed a substantial reduction of residual oil saturation from 6 to $12 \%$ of original oil in place after LSW flooding, using single well chemical tracer test. Lager et al. (2008b) have also observed this phenomenon in North Slope of Alaska. Skrettingland et al. (2011) confirmed the efficiency of LSW flooding during his core flooding experiments and SWCTT field pilot in the North Sea. Moreover, there are several researches which compared the effectiveness of sea water injection due to its lower salinity over the injection of produced water (Austad et al. 2005; Hognesen et al. 2005).

Although most of the researchers had focused on the low-salinity water flooding in sandstone porous media type, Austad et al. $(2007,2011)$ performed many researches on this matter in limestone or carbonate rock type. Recently, they conducted some experimental tests on chalk core using modified sea water and different oil phase compositions and observed that in the absence of anhydrite in the rock formation, there were no effects of LSW flooding (Austad et al. 2011). In another work performed by Fathi et al. (2010), the effect of salinity and ionic composition of LSW was investigated on oil recovery in chalk porous media at elevated temperature. Based on this research, the chemical interaction of some ions such as $\mathrm{Mg}^{2+}, \mathrm{Ca}^{2+}$ and $\mathrm{SO}_{4}^{2-}$ at chalk surface increases water wetness. Wettability alteration had been also confirmed by contact angle measurements during sea water contacting with carbonate core in the study done by Yousef et al. (2011). Also, the relative permeability shift (Nasralla et al. 2014), residual oil saturation reduction (Nasralla et al. 2014) and capillary pressure were demonstrated by researches during sea water injection (Webb et al. 2005b).

\section{Mechanisms}

Nowadays, the interest in using LSW flooding to improve oil recovery has intensified, but no specific mechanism has been proposed yet. Some researchers such as Tang and Morrow (1997) have shown that oil/water relative permeability changes through LSW injection processes and rock wetting condition tends to be more water wet; therefore, oil relative 
permeability increases at a given water saturation, which causes less oil trapping in pore structures. However, the complexity of mineral, oil and aqueous-phase compositions create severe conditions for interpreting the reasons of this phenomenon (Atthawutthisin 2012).

Different physicochemical mechanisms have been proposed to validate wettability alteration as one of the primary causes of oil recovery enhancement by LSW flooding in sandstone and carbonate rocks. These mechanisms are classified as salting-in, multiple ion exchange (MIE), fines migration, EDL expansion, mineral dissolution, and $\mathrm{pH}$ modification (Purswani et al. 2017).

Salting-in mechanism was proposed by Austad et al. (2010) for sandstone reservoirs, where they suggested that clay particles act as cation exchangers on the sandstone surface. Similar mechanism was also proposed for carbonate rocks, which is described as rock dissolution mechanism and it is a consequence of the process of wettability alteration as the divalent ions migrate from the rock surface toward the brine.

To illustrate the phenomenon of rock dissolution in carbonate reservoirs, zeta potential measurements were performed by Yousef et al. (2011), as it has been widely applied for determining the surface charge of a rock in a particular brine environment (Esmaeili et al. 2016; Rahbar et al. 2017; Vinogradov et al. 2010). Their results revealed a reduction of the carbonate surface zeta potential with a decrease in brine salinity, which suggested that $\mathrm{Ca}^{2+}$ ions migrated from the rock surface toward the low-salinity brine to re-establish chemical equilibrium between the bine and rock (Purswani et al. 2017). Moreover, the decrease in the positive charge on the carbonate surface in presence of low-salinity water led to the expansion of the electric double layer (EDL) and resulted in a thicker, more stable water film.

EDL expansion has been also considered as a possible mechanism for wettability alteration in sandstone reservoirs, which highly depends on the electrostatic interaction between the brine/oil and brine/rock interfaces (Myint and Firoozabadi 2015; Nasralla and Nasr-El-Din 2014) and is a function of the $\mathrm{pH}$ and salinity of the brine, as well as the cation type surrounding the clay or sandstone particle. Based on this mechanism, the EDL expands both at the oil/ brine interface and at the rock/brine interface as low-salinity water is injected. The expansion of EDL results in an overlap between both EDLs, which leads to an increase in the repulsive forces between them. When these repulsive forces exceed the binding forces between the acidic groups in oil and the clay surface, the water layer between the oil and clay surface expands, resulting in desorption of the oil particles from the clay surface and an increase in water-wetness of the surface (Hilner et al. 2015; Myint and Firoozabadi 2015).

Multiple ion exchange (MIE) is another mechanism that impacts the process of wettability alteration in carbonate rocks, which is a cumulative interplay of the divalent ions $\left(\mathrm{Mg}^{2+}, \mathrm{Ca}^{2+}\right.$ and $\left.\mathrm{SO}_{4}^{2-}\right)$ from the brine, together with the rock and crude oil (Zhang et al. 2007a). Based on this mechanism and the reactions shown in Eqs. (1) and (2), $\mathrm{SO}_{4}^{2-}$ ions, presenting in the brine phase, are attracted toward the surface of carbonate rocks due to the positive surface charge of carbonates, resulting in surface potential reduction which attracts the divalent positive ions closer to the surface. Depending on the temperature, either $\mathrm{Ca}^{2+}$ ions (below $70{ }^{\circ} \mathrm{C}$ ) or $\mathrm{Mg}^{2+}$ ions (above $100^{\circ} \mathrm{C}$ ) show higher activity close to the rock surface and interact with the negative carboxylic end of the crude oil attached to the carbonate surface. It is notable that in presence of more positive ions in the solution, stronger interaction occurs with the carboxylic end, as opposed to the attraction between crude oil and carbonate surface, which release the oil particles from the rock surface and results in improved oil recovery (Zhang et al. 2007a).

$$
\begin{aligned}
& \mathrm{RCOO}^{-}-\mathrm{Ca}-\mathrm{CaCO}_{3}(\mathrm{~S})+\mathrm{Ca}^{2+}+\mathrm{SO}_{4}^{2-} \\
& \quad=\mathrm{RCOO}-\mathrm{Ca}^{2+}+\mathrm{Ca}-\mathrm{CaCO}_{3}(\mathrm{~S})+\mathrm{SO}_{4}^{2-} \\
& \mathrm{RCOO}^{-}-\mathrm{Ca}-\mathrm{CaCO}_{3}(\mathrm{~S})+\mathrm{Mg}^{2+}+\mathrm{SO}_{4}^{2-} \\
& \quad=\mathrm{RCOO}_{-} \mathrm{Ca}^{2+}+\mathrm{Mg}-\mathrm{CaCO}_{3}(\mathrm{~S})+\mathrm{SO}_{4}^{2-}
\end{aligned}
$$

There has been several attempts to model the wettability alteration during LSW flooding by interpolating relative permeability, capillary pressure, and residual oil saturation between two wetting states (Delshad et al. 2009; Jerauld et al. 2008). In 2006, Jerauld et al. (2006a, b) simulated the LSW injection by applying the conventional fraction-flow theory to describe secondary and tertiary LSW process in 1D reservoir. Their developed model was able to estimate the relative permeability during the mixing of low-salinity with high-salinity water in the reservoir. They also demonstrated that fine-grid simulation is not basically necessary to represent dispersion and it can be easily lifted by defining a salinity dependency of relative permeability. Threedimensional simulation of LSW flooding on a heterogeneous synthetic reservoir was carried out using Eclipse 100 software by Atthawutthisin (2012). Shojaei et al. (2015) performed a series of experimental LSW flooding tests on a sandstone core aged with crude oil and obtained the relative permeability and capillary pressure curve using Sandra simulator through history matching method. They indicated that residual oil saturation changed linearly with injection brine salinity due to the IFT reduction and wettability alteration toward more water-wet. In another study, Omekeh et al. (2012) coupled a MIE process relevant to a standard Buckley-Leverett two-phase model to study the wettability alteration mechanism in an oil-wet sandstone rock during LSW flooding. They observed that various compositions

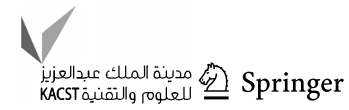


of brine give different oil recovery curves as the result of different ranges of divalent ions (calcium and magnesium) desorption.

A simple model was developed by Yu et al. (2009) and Andersen et al. (2012) to consider wettability alteration during LSW flooding by including one or two chemical species. However, Qiao et al. (2014) mentioned that this method was not sufficient to capture the complex interactions between multiple components in brine, oil, and solid surface. A surface complexation model was used by Brady et al. (2012) with reaction networks relevant to carbonate and sandstones. However, they did not couple their model with multiphase flow to understand dynamic effects on wettability alteration (Qiao et al. 2014). A mechanistic model was then developed by Qiao et al. (2014) which coupled multiphase flow and transport by considering a detailed surface and aqueous multicomponent reaction network to capture the competitive interactions among oil, brine, and the surface of the Stevns Klint chalk. They further extended their model to include limestone surface complexation and mineral dissolution/precipitation reactions to provide a model for LSW flooding in different carbonate reservoirs with different mineralogy (Qiao et al. 2016).

\section{The motivation of this study}

In this study, we established a synthetic two-phase reservoir model in three dimensions containing specific permeability and porosity distribution maps. Moreover, there is a gap in the literature as none of them considered the effect of the required time for wettability alteration in oil/brine system at reservoir conditions; while the results of the research done by Mahani et al. (2011), confirmed that wettability alteration process in low-salinity water injection takes an aging time about $240 \mathrm{~h}$. Some researchers such as Yildiz and Morrow (1996), Morrow et al. (1998), Webb et al. (2005a), Jerauld et al. (2006a, b) and Atthawutthisin (2012) have also shown that wettability alteration intensifies only in certain ranges of low-salinity concentrations. Therefore, the present study is aimed to investigate the effect of aging time of wettability alteration process on oil recovery and also to determine the simulated oil recovery sensitivity on salinity threshold. In the last section of current simulation, various amounts of injection brine salinity in different ranges of salinity thresholds are chosen to figure out the behavior of wettability alteration and to prove that a particularly optimized salinity might be existed for reaching the maximum oil recovery with minimum implementation cost. It should be considered that the model presented by other researchers is used in this study to handle the transient behavior of relative permeability function in LSW injection. Furthermore, to simulate the LSW flooding process, MATLAB software computer programming is employed.

\section{Model description}

The general reservoir dimensions are $3420 \times 3420 \times 90 \mathrm{ft}^{3}$ which totally includes 4563 simulation grid blocks in Cartesian coordinate. This model constructed by three layers in which each layer consists of 39 grid blocks in $x$ and the same amount in $y$-direction. We carried out our simulations on a relatively small reservoir with enough number of simulation grid block to capture the accurate result for each studying section. The sensitivity analysis was also performed to minimize the effect of grid block size on the simulation result. A five-spot pattern is chosen for LSW flooding model including four injection wells (Inj-Well\#1 through Inj-Well\#4) at corners of bottom layer and one production well (Prod-Well\#5) located at the center of top layer. Further assumptions for this two-phase (dead oil/brine) flow model are summarized as follows:

- The porosity and permeability map are heterogeneous.

- The production well produces under constant bottomhole pressure and four injection wells operate under constant injection rate condition.

- All reservoir layers are completely placed in the oil zone.

- Temperature remains constant during the simulation process.

Other reservoir characteristics including rock and fluids properties and operational conditions of injection/production wells are listed in Table 1. The provided values in this table are used in the "base case" for model validation and in the "general model" for studying LSW flooding. The results of the base case are compared to one of the commercial petroleum engineering software for validation.

To avoid unreliable results obtained from the simulation of LSW flooding, the relative permeability and capillary pressure curves under high- and low-salinity condition were extracted from a recent research conducted by Omekeh et al. (2013). These high- and low-salinity relative permeability functions which were used for the general model are shown in Fig. 1a. This figure indicates oil wetness behavior at the initial state of the reservoir and more water wetness after low-salinity water flooding, based on Craig's rule (1971). As it can be seen in Fig. 1b, LSW imbibition capillary pressure curve is situated above HSW curve which proves that the spontaneous imbibition in LSW condition is more dominant in comparison to HSW condition. By assumption of water flood injection at irreducible water saturation in this study, 
Table 1 Basic reservoir properties of base case $(*)$ for validation and general model $(* *)$

\begin{tabular}{ll}
\hline Parameters & Values of base case for validation \\
\hline Grid blocks system $\left(^{*}\right)$ & $11 \times 11 \times 3$ \\
Grid blocks system $\left(^{* *}\right)$ & $39 \times 39 \times 3$ \\
Grid blocks size $(*)(* *)$ & $\mathrm{d} x=87.7 \mathrm{ft}, \mathrm{d} y=87.7 \mathrm{ft}, \mathrm{d} z=30 \mathrm{ft}$ \\
Horizontal-vertical permeability $\left(^{*}\right)$ & $250-25 \mathrm{mD}$ \\
Porosity $(*)$ & 0.20 \\
Reservoir temperature $(*)(* *)$ & $179.6^{\circ} \mathrm{F}$ \\
Oil density $(*)(* *)$ & $46.8 \mathrm{lb} / \mathrm{ft}^{3}$ \\
Oil viscosity $(*)(* *)$ & $1.3 \mathrm{cp}$ \\
Water rate injection of each $(*)(* *)$ & $2000 \mathrm{STB} / \mathrm{day}$ \\
Water viscosity $(*)$ & $0.5 \mathrm{cp}$ \\
Water compressibility factor $(*)$ & $6 \times 10^{-6} 1 / \mathrm{psi}$ \\
Water formation volume factor $(*)$ & $1.01 \mathrm{bbl} / \mathrm{STB}$ \\
Oil compressibility factor $(*)(* *)$ & $5 \times 10^{-5} 1 / \mathrm{psi}$ \\
Oil formation volume factor $(*)(* *)$ & $1.3 \mathrm{bbl} / \mathrm{STB}$ \\
Production well bottom hole pressure $(*)(* *)$ & $1500 \mathrm{psi}$ \\
\hline
\end{tabular}
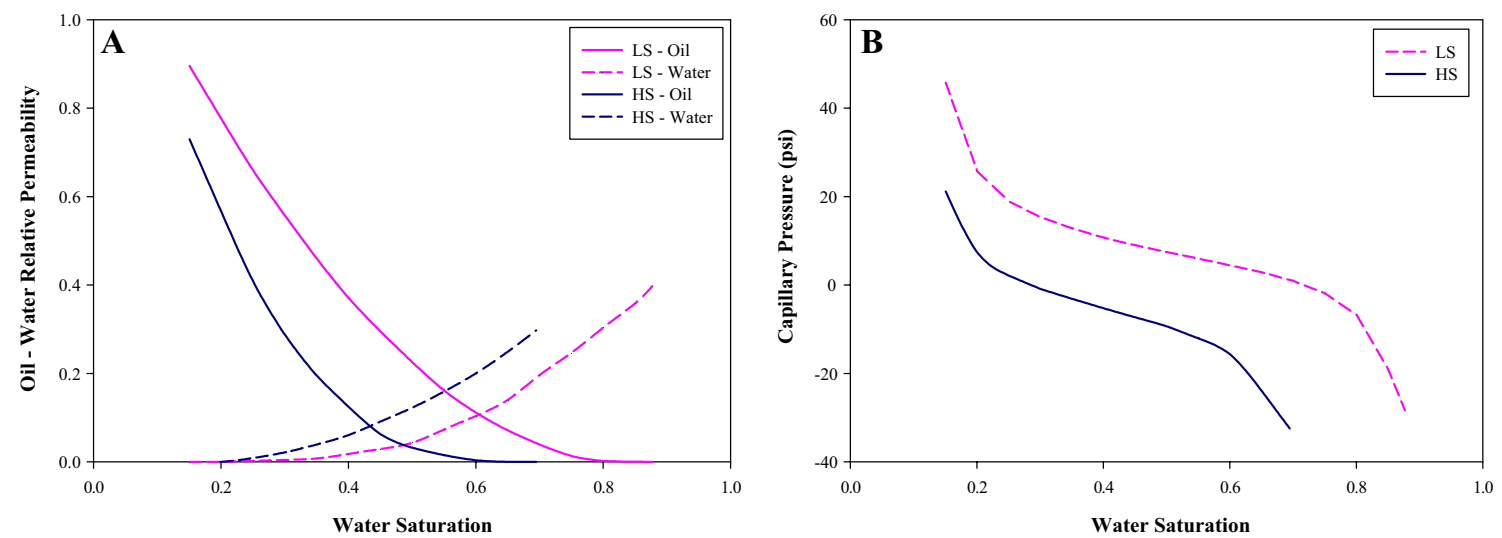

Fig. 1 a Oil/water relative at HSW and LSW conditions, b comparison of capillary pressure between HSW and LSW condition (Omekeh et al. 2013)

the imbibition capillary pressure curve must be applied rather than drainage capillary pressure. Note that the same two-phase relative permeability curves under high-salinity condition are used for base case simulation.

As already has been mentioned, unlike the base case which is used for validation, porosity and permeability distribution maps are established in the general model. The uncertainties in the reservoir field data such as porosity and permeability indisputably have a great influence on the results of the simulation, thus this issue must be considered in any reservoir simulation to make the simulation closer to the real condition. In order to have more reliable distribution maps in which the absolute permeability value in each direction be a proposition to porosity value, a correlation between porosity and permeability data is assumed based on previous research by other scholars (Tiab and Donaldson 2015). At first, the porosity map is created for each layer by random generation tools of MATLAB software using a normal distribution function with the standard deviation of 0.002 and the mean value of 0.17 . This empirical correlation is shown as follows in Fig. 2 and expressed in Eqs. (3) and (4) for horizontal and vertical direction, respectively.

It is a routine assumption that the vertical absolute permeability is than the horizontal absolute permeability; therefore, the values of permeability in $x, y$ and $z$-directions vary from 106 to $49 \mathrm{mD}, 106$ to $492 \mathrm{mD}$, and 10.6 to $49.2 \mathrm{mD}$, respectively. Porosity values are also in the ranges of $0.164-0.176$ which is shown in Fig. 3. To isolate the effect of low-salinity water injection on the results, the distribution maps remain constant for all of the cases used in this study.

$$
\begin{aligned}
& k_{x}, k_{y}(\mathrm{mD})=9 \times 10^{17} \times \phi^{20.135}, \\
& k_{z}(\mathrm{mD})=9 \times 10^{16} \times \phi^{20.135}
\end{aligned}
$$




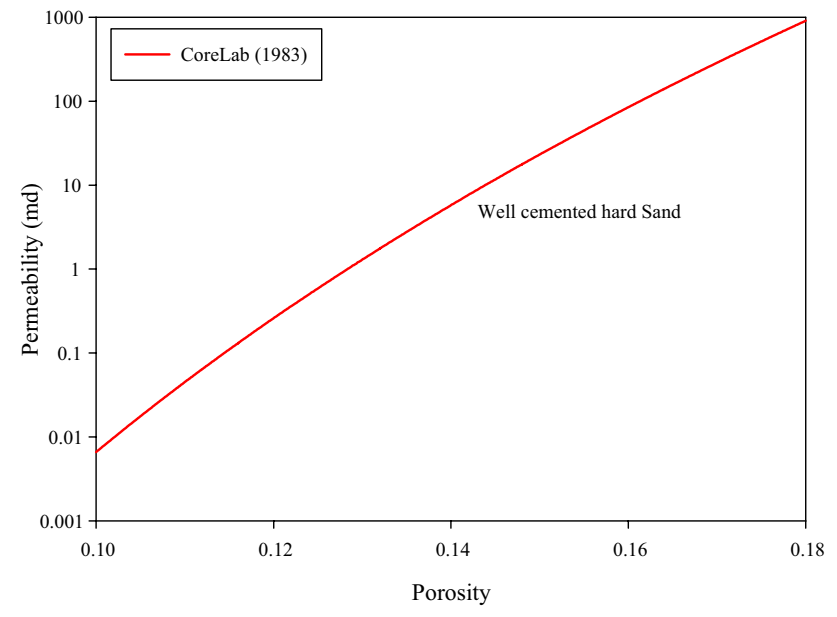

Fig. 2 The correlation between horizontal absolute permeability and porosity (Tiab and Donaldson 2015)

\section{Calculation of fluid properties and solving governing equation}

\section{Governing equations and solving approach}

The current simulation must handle the two-phase flow system with a salt phase added in the aqueous phase; therefore, three continuity equations for water, oil and brine concentration must be solved. In this paper, the governing equations for two-phase flow in three dimensions are referred to the equations arranged by Ertekin et al. (2001). Finite difference method is applied for discretizing the governing equations. The discretization scheme of equations is out of the scope of this paper because they are fully addressed elsewhere (Ertekin et al. 2001). To solve the governing equation and compute the water saturation, oil phase pressure and brine concentration, fully implicit approach is undertaken and the relevant programming code is established in MATLAB software. The fully implicit approach along with small time step and small block size is selected to prevent any possible numerical dispersion in our simulations. However, the material balance is checked continuously to ensure that numerical dispersion is not happened in each time step, though the sensitivity analysis for grid block size had been carried out before. It is notable that upstream weighting scheme is employed to calculate the transmissibility terms during this simulation.

\section{Calculation of brine properties}

One of the most challenging issues in brine flooding simulation at reservoir condition is the evaluation of brine properties as a function of temperature, pressure, brine composition and salt concentration. Fortunately, a wide number of studies had been done in this area (Gibson and Loeffler 1941; Hilbert 1979; Osif 1988; Rowe Jr and; Chou 1970). In this paper, an accurate empirical correlation expressed by Spivey et al. (2004) is used. The advantage of this correlation compared to others is that it is compatible with different reservoir conditions in wide ranges of temperature, pressure, and salinity up to $275^{\circ} \mathrm{C}, 200 \mathrm{MPa}$, and $5.7 \mathrm{~mol} / \mathrm{L}$, respectively. In 1981, Kestin et al. (1981) proposed a set of empirical correlations to predict brine dynamic viscosity as a function of temperature in the ranges of $20-160{ }^{\circ} \mathrm{C}$ and pressure between 0.1 and $35 \mathrm{MPa}$ and salinity up to 6 molars for $\mathrm{NaCl}$ solution. Note that the reservoir temperature in this simulation is lower than $160{ }^{\circ} \mathrm{C}$. All required empirical correlations which are adapted for the simulation are summarized in the Appendix 1.

\section{Model validation}

To validate the model implemented by the fully implicit method, the results of the developed code was compared with one of the commercial petroleum engineering software results. The parameters required in the base case for model validation are summarized in Table 1 . The base model has 363 simulation grid blocks and the saturation functions are considered according to Fig. 1. To fairly evaluate the performance of the developed code, only field oil recovery, average field pressure (oil phase pressure) and production well water cut are compared. In other words, the contribution of all effective parameters in the reservoir simulation appear in field oil recovery, average field pressure and production well water cut results. The values of field oil recovery, production well water cut, and average field pressure versus time for the developed code in comparison with commercial petroleum engineering simulator are plotted in Fig. 4a. The results surprisingly indicate that the oil recovery and production well water cut data of the developed code are in good agreement with the commercial software results. As can be seen in this figure, both field oil recovery and well water cut curve for developed code and commercial software are overlapping on each other. Figure 4 demonstrates that the results of the developed core pursue the obtained result of the commercial simulator. The largest pressure difference between the results of the developed code and commercial simulator is equal to $5.3 \mathrm{psi}$, with a relative error of approximately $0.158 \%$ at the time of 487 days, which is negligible. This difference could be attributed to the interpolation function that is used to compute fluid properties for a given set of data. The greatest uncertainty is related to oil/water relative permeability values during simulation process because a finite set of data is only given to both code and software, thus the interpolation technique which is used to predict these parameters can be 


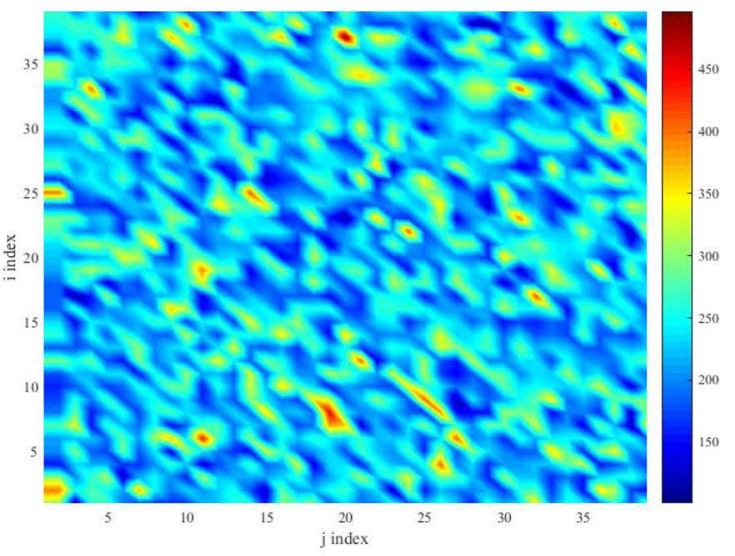

First layer horizontal permeability map

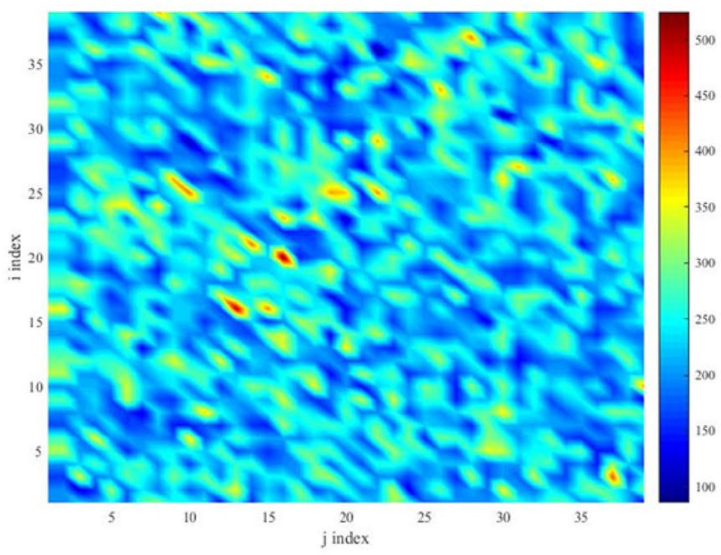

Second layer horizontal permeability map

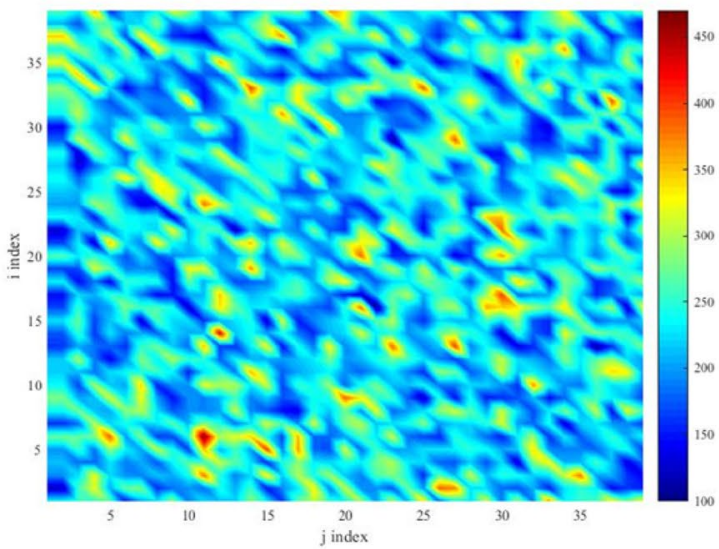

Third layer horizontal permeability map

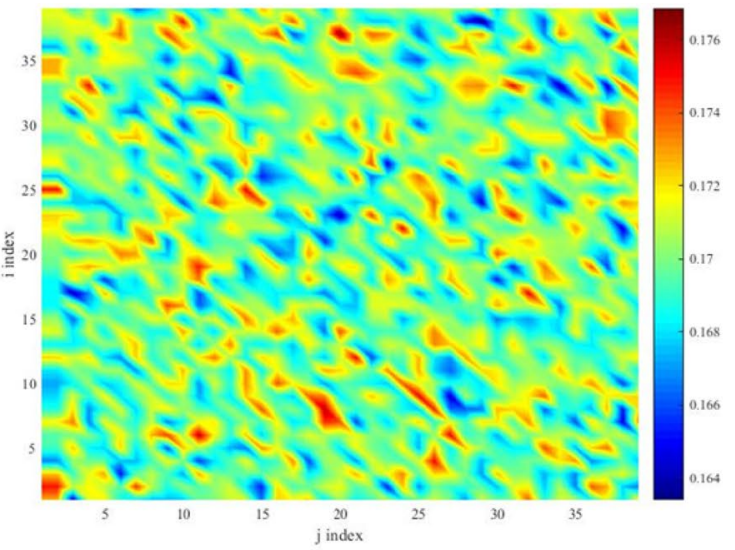

First layer porosity map

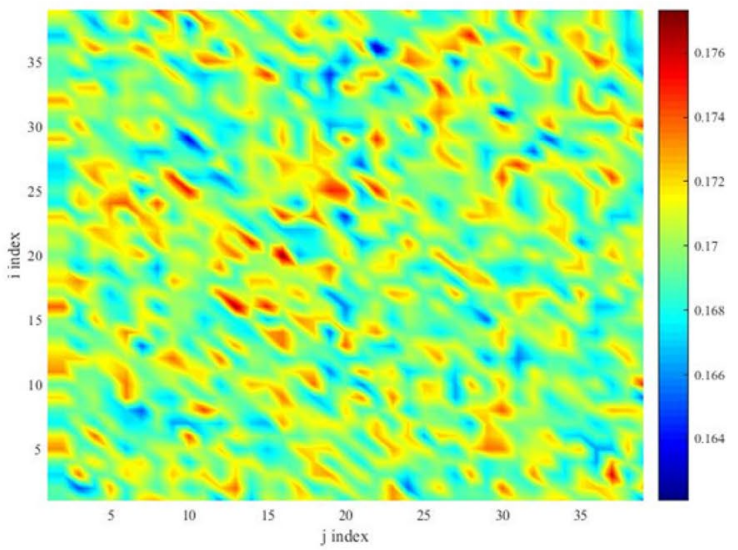

Second layer porosity map

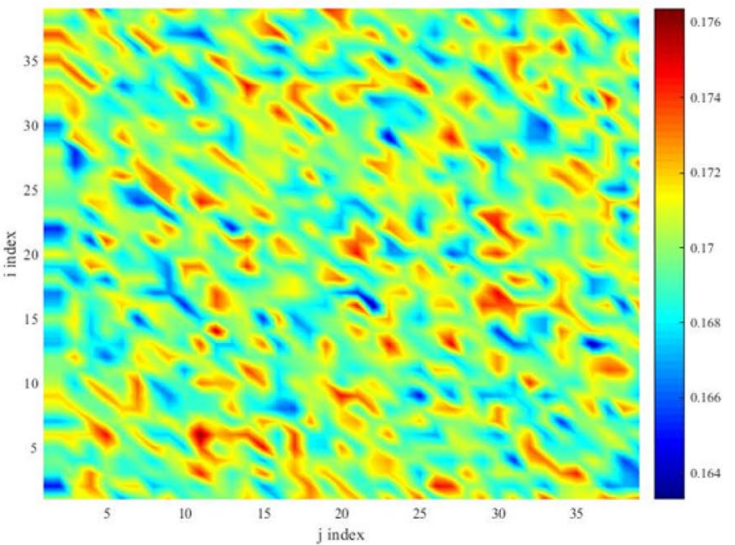

Third layer porosity map

Fig. 3 Permeability and porosity distribution map. Right side: $X$-direction permeability map, left side: porosity distribution map

different. However, the criterion for reaching convergence is another uncertain parameter.

To compare the result of the developed code for the base case with that obtained using the commercial simulator, Table 2 presented some statistical parameters such as the absolute relative deviation, absolute deviation, maximum absolute deviation and maximum absolute relative deviation among 1000 time-steps for this simulation. According to this table, the developed code can simulate the two-phase flow exactly the same as commercial software, so it has the 
capability to be extended for LSW flooding in a synthetic reservoir model.

To better understand the difference between the results generated by the developed code and commercial software, for instance, the results of absolute deviation of average field pressure and oil recovery from obtained value of commercial software during simulation time is clearly shown in Fig. 5. It can be mentioned that the Buckley-Leveret theory can be implemented to validate the results of this developed code; however, this approach is ignored due to some difficulties in establishing this theory under the presence of gravity force and capillary pressure in water flooding process. Furthermore, considering the compressible fluid flow in porous media makes this problem more severe; hence, a commercial simulator is used for validation.

\section{Effective factors in LSW flooding simulation}

In this section, the general model is used to investigate the effect of some parameters such as salinity threshold range, injection brine salinity, and aging time on oil production
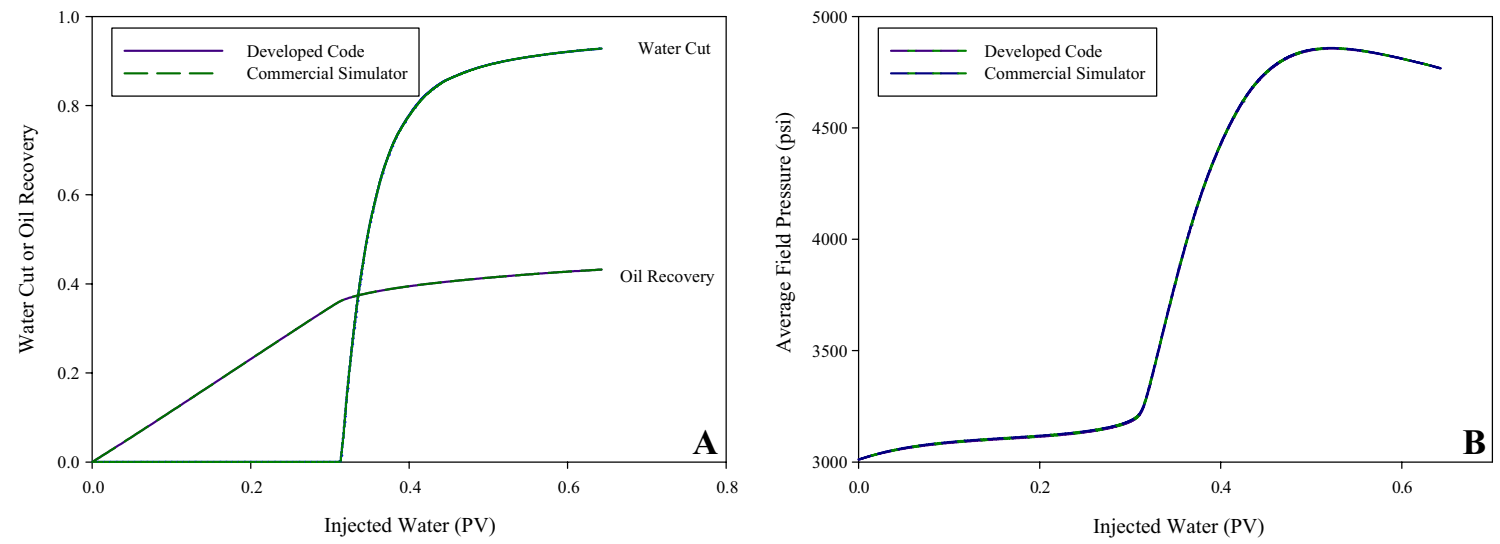

Fig. 4 a Comparison of the field oil recovery and well water cut, and $\mathbf{b}$ comparison of average field pressure values between the developed code and the commercial simulator

Table 2 Statistic parameters for comparing the result of base case obtained by developed core and commercial simulator

\begin{tabular}{llll}
\hline Parameters & Average field pressure & Oil recovery & Water cut \\
\hline Maximum absolute deviation (psi or \%) & 5.48 & $1.60 \times 10^{-2}$ & $1.22 \times 10^{-1}$ \\
Maximum absolute relative deviation (\%) & $1.6 \times 10^{-1}$ & $2.74 \times 10^{-1}$ & $1.01 \times 10^{-1}$ \\
Absolute deviation at the end (psi or \%) & $5.84 \times 10^{-1}$ & $2.1 \times 10^{-4}$ & $1.94 \times 10^{-2}$ \\
Absolute relative deviation at the end (\%) & $1.22 \times 10^{-2}$ & $8.62 \times 10^{-3}$ & $2.09 \times 10^{-2}$ \\
\hline
\end{tabular}
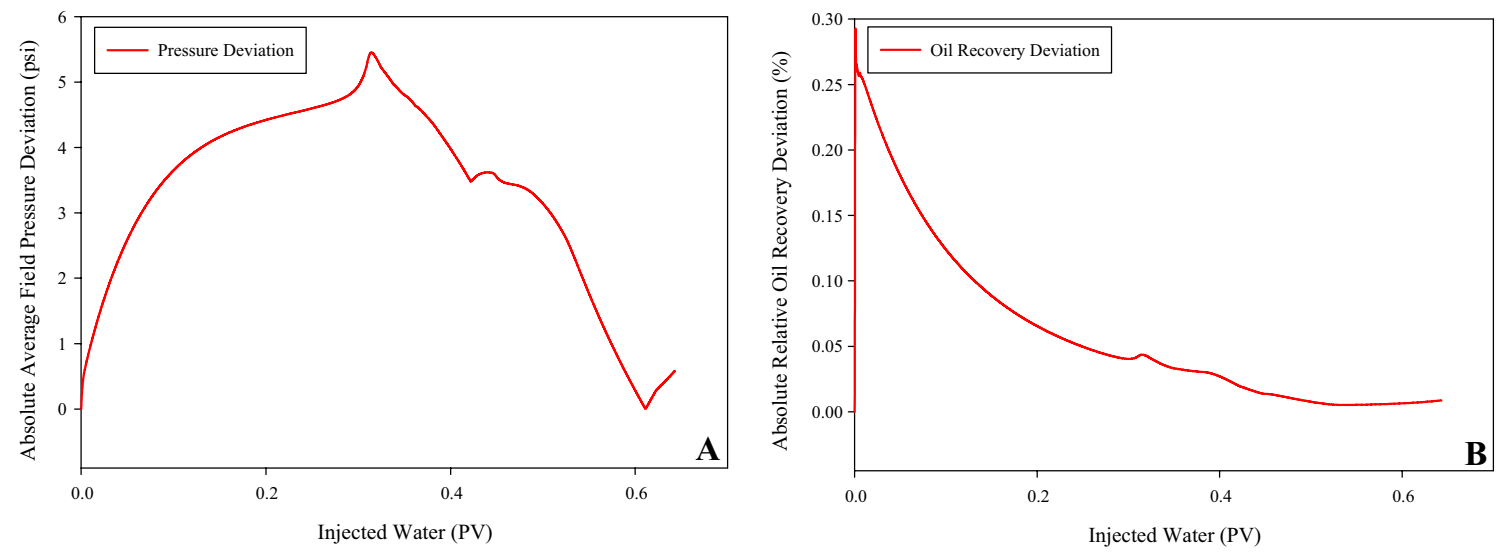

Fig. 5 Comparison of absolute deviation of $\mathbf{a}$ average field pressure, and $\mathbf{b}$ oil recovery between the developed code and the commercial simulator 
performance during LSW flooding. The salinity threshold range and aging time are required to be considered in wettability alteration process. The formation brine salinity is about $160 \mathrm{~g} /$ liter $\left(77 \mathrm{gmol} / \mathrm{ft}^{3}\right.$ water). In addition, the simulation process has continued about 4500 days after low-salinity water injection. Afterward, the recovery curve, the values of water cut and average field pressure are reported.

In transient condition under low-salinity water flooding, where high-salinity water is blended with low-salinity water, oil/water relative permeability and capillary pressure are modified between the values corresponding to low-salinity water and high-salinity water using weighting coefficients. Equations (5) -(7) are the representative correlations for oil/ water relative permeability and capillary pressure calculations during transient condition from high salinity to low salinity, respectively. The parameter $F_{1}$ is weighting coefficient as a function of brine salinity.

$k_{\mathrm{ro}}=F_{1} \cdot k_{\mathrm{ro}}^{\mathrm{HSW}}+\left(1-F_{1}\right) \cdot k_{\mathrm{ro}}^{\mathrm{LSW}}$,

$k_{\mathrm{rw}}=F_{1} \cdot k_{\mathrm{rw}}^{\mathrm{HSW}}+\left(1-F_{1}\right) \cdot k_{\mathrm{rw}}^{\mathrm{LSW}}$,

$P_{\mathrm{c}}=F_{1} \cdot P_{\mathrm{c}}^{\mathrm{HSW}}+\left(1-F_{1}\right) \cdot P_{\mathrm{c}}^{\mathrm{LSW}}$.

The above methodology was described by Atthawutthisin (2012) as a representative correlation during the transient region of LSW flooding which is employed in this simulation. A linear dependence of relative permeability within the salinity threshold range was introduced by Jerauld et al. $(2006 \mathrm{a}, \mathrm{b})$. This proposed model was also expressed by Shojaei et al. (2015) and then modified for analyzing their experimental results. The model developed by Jerauld et al. (2006a, b) is pointed out as follows:

$k_{\mathrm{ro}}=\theta \cdot k_{\mathrm{ro}}^{\mathrm{HSW}}\left(S^{*}\right)+(1-\theta) \cdot k_{\mathrm{ro}}^{\mathrm{LSW}}\left(S^{*}\right)$,

$k_{\mathrm{rw}}=\theta \cdot k_{\mathrm{rw}}^{\mathrm{HSW}}\left(S^{*}\right)+(1-\theta) \cdot k_{\mathrm{rw}}^{\mathrm{LSW}}\left(S^{*}\right)$,

$P_{\mathrm{c}}=\theta \cdot P_{\mathrm{c}}^{\mathrm{HSW}}\left(S^{*}\right)+(1-\theta) \cdot P_{\mathrm{c}}^{\mathrm{LSW}}\left(S^{*}\right)$,

$\theta=\left(S_{\text {orw }}-S_{\text {orw }}^{\mathrm{LSW}}\right) /\left(S_{\text {orw }}^{\mathrm{HSW}}-S_{\text {orw }}^{\mathrm{LSW}}\right)$,

$S^{*}=\left(S_{o}-S_{\text {orw }}\right) /\left(1-S_{\mathrm{wr}}-S_{\text {orw }}\right)$.

\section{Effect of salinity threshold and weighting coefficients on oil recovery}

An attempt is made to investigate the effect of transient behavior of HSW to LSW condition on ultimate oil recovery, so three different ranges of salinity threshold were proposed. These salinity threshold ranges were chosen to assess their importance on wettability alteration process and oil recovery performance during low-salinity water injection. Jerauld et al. (2006a, b) used some weighting factors to calculate the oil/water relative permeability in transient behavior from HSW to LSW which are summarized in
Table 3 Weighting coefficient for wettability alteration in Jerauld studies (2006a, b)

\begin{tabular}{ll}
\hline $\begin{array}{l}\text { Brine salinity } \\
(\mathrm{ppm})\end{array}$ & $\begin{array}{l}\text { Weighting } \\
\text { coefficient }\end{array}$ \\
\hline 0 & 1 \\
10 & 0.9 \\
100 & 0.8 \\
1000 & 0.7 \\
5000 & 0.3 \\
10,000 & 0.2 \\
20,000 & 0.1 \\
40,000 & 0 \\
\hline
\end{tabular}

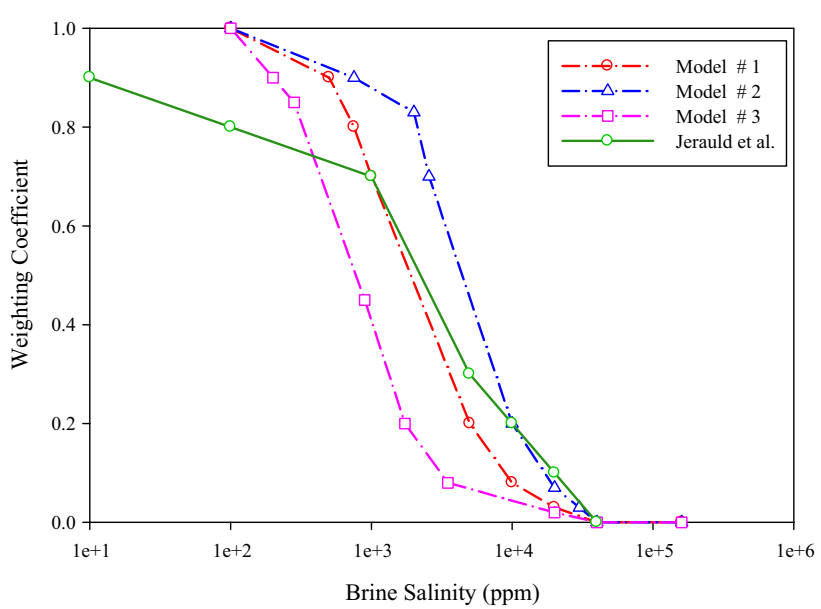

Fig. 6 Value of weighting factor of this study and Jerauld study $(2006 \mathrm{a}, \mathrm{b})$

Table 3 and illustrated in Fig. 6. The three salinity threshold ranges proposed in this study are also shown in Fig. 6, which are selected between $750-5000 \mathrm{ppm}, 2000-10,000 \mathrm{ppm}$ and 300-2000 ppm for model\#1, model\#2 and model\#3, respectively.

It can be seen that values of weighting factor at the beginning and end of all threshold salinity ranges were approximately equal to 0.2 and 0.8 . Moreover, in all models, the injection brine salinity is set to $500 \mathrm{ppm}$ for all injection wells and brine injection has taken place at the beginning of each run. Since the injection rate, injection water salinity and simulation time remain constant during the simulation process, the salinity threshold effect on the ultimate oil recovery is separated from other effects in this section.

\section{Effect of aging time in wettability alteration process on oil recovery}

None of the previous simulation studies had investigated the effect of aging time on oil recovery although Mahani et al. (2011) confirmed the fact that it takes approximately 180-240 h for altering the wettability state of rock surface 
during the LSW flooding. They visually observed that the contact angle between oil drop and rock surface is incrementally changed from $90^{\circ}$ to $30^{\circ}$ during $12,000 \mathrm{~min}(200 \mathrm{~h})$ in their experiments. This aging time may lead to a delay time which appears in field oil recovery; therefore, some unmistakable financial damages can occur if this time is not considered in field reservoir simulation. The assumption of such an issue in reservoir simulation processes seems a little complicated and unfortunately has not been mentioned in commercial software; however, this study expresses a brief description of this implementation in the developed code.

In a particular grid block, when the brine salinity is changing from a specific value to another new value, the proportional weighting factor to this new value should not be changing immediately; instead, it should be changing at 10 days later, for instance. To implement the aging time in this simulation study, the weighting factor of each block at all time-steps are required to be stored during simulation. It should be mentioned that the general model is implemented in this study and the weighting factor of model\#2 (refer to Fig. 6) is used to handle the transient behavior of HSW to LSW flooding. To study the effect of aging time on oil recovery, three different aging times are chosen for model\#4, model\#5 and model\#6. In model\#4, we supposed that wettability alteration has occurred instantly after changing brine salinity; however, the aging process for model\#5 and model\#6 are assumed to take 4 and 10 days after brine salinity modification. The values of oil recovery, water cut, and average field pressure are provided to evaluate these models.

\section{Effect of injection brine salinity selection along with salinity threshold on oil recovery}

As pointed out previously, the considerable modification of surface rock wettability is theoretically occurred at a specific salinity threshold range; therefore, decreasing the brine salinity more than a particular value does not intensify the wettability alteration process as demonstrated in Fig. 6. Thus, careful sensitivity analysis must be undertaken before any implementation of LSW flooding, especially at the field scale, where we expect a high oil recovery according to our expenses. This issue is more important in present circumstances that oil price is falling down. Due to the complexity of oil price fluctuation and the cost of salinity reduction process, we only focus on oil recovery and other parameters rather than economic arguments.

The general model was run with various injection brine salinity until the specific time (4500 days) to perform the sensitivity analysis on different injection brine salinity at various salinity threshold ranges within LSW flooding. For better interpretation, values of injection brine salinity were selected in the ranges of 200 to $20,000 \mathrm{ppm}$, which incrementally changed by $200 \mathrm{ppm}$ in ranges of $200-5000 \mathrm{ppm}$. The simulation studies were conducted using the weighting coefficient of model\#1 through model\#3 to implement the transient behavior of low-salinity water flooding. Brine is also injected at the beginning of the simulation process for all runs by considering no aging time.

\section{Results and discussion}

\section{Effect of salinity threshold and weighting coefficients on oil recovery}

Figure 7 clearly shows the effect of salinity threshold and weighting coefficient on oil recovery during the low-salinity water flooding in the general model. According to this figure, LSW flooding causes an improvement in oil efficiency by $12.02 \%, 10.31 \%$ and $7.52 \%$ for three models in comparison to the high-salinity water flooding. Moreover, the maximum oil recovery is corresponding to model $\# 2$ in which the salinity threshold range is between 2000 and 10,000 ppm.
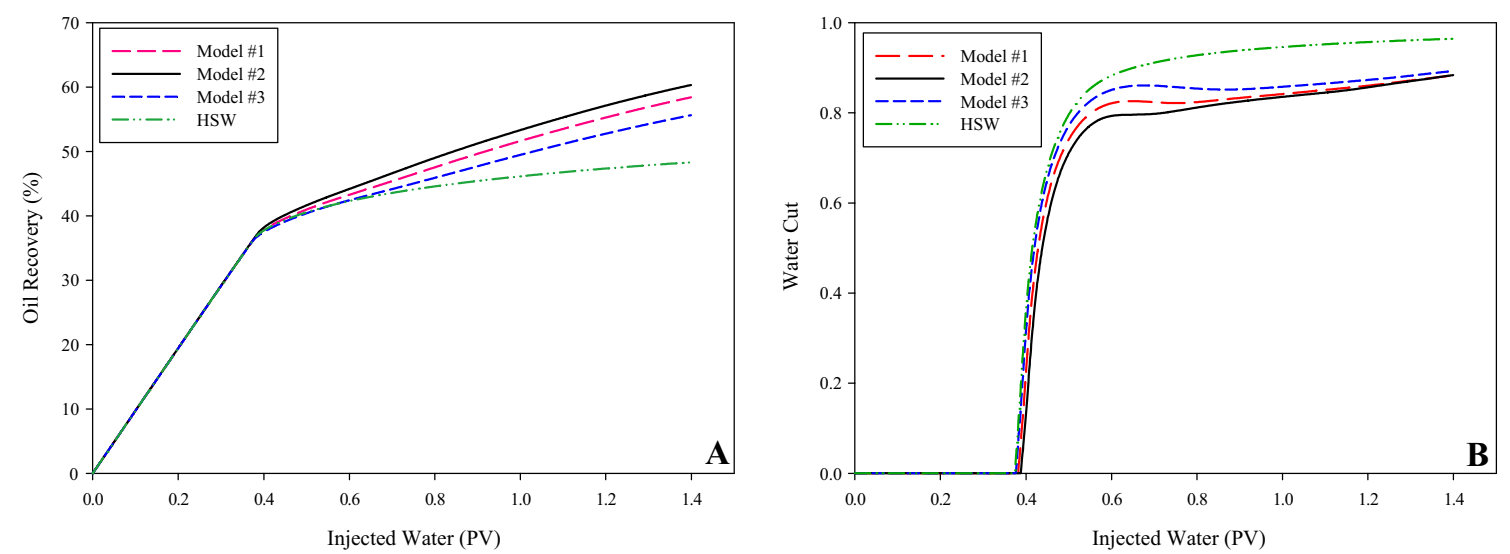

Fig. 7 Effect of salinity threshold and weighting coefficient on a LSW oil recovery, and b well water cut

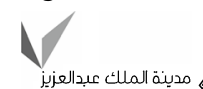

年 Springer 
One of the most important reasons for this result is attributed to the wide range of salinity threshold for this model, which leads wettability alteration to occur earlier than other models and consequently modifies the water relative permeability and postpones the breakthrough time. In addition, oil can be displaced more easily due to the higher oil relative permeability, resulting in higher oil production. This result is also consistent with previous studies performed by other researchers (Jadhunandan and Morrow 1995; Lager et al. 2008a; Shojaei et al. 2015; Webb et al. 2008). Narrow ranges of salinity threshold might have an adverse effect on oil recovery during low-salinity water flooding because wettability alteration process happens at later times after low-salinity water injection and it takes more time to reduce the brine salinity to such a low value; for instance, $2000 \mathrm{ppm}$ in the model\#3.

Figure 7 indicates that breakthrough times for model\#2, model\#1 and model\#3 happen at 54 days (0.0168 PV), 30 days (0.0093 PV), and 19 days (0.0059 PV) after HSW breakthrough time, respectively. This issue has also shown in the plot of well water cut versus pore volume of water injected, in which the amount of well water cut suddenly increased from zero value. It should be pointed out that three models have the same oil recovery factor until 1241 days [breakthrough time $(0.389 \mathrm{PV})$ ], which reveals that there is no effect of low-salinity brine injection on oil recovery up to this time. The results also express that the general model with a weighting coefficient of model $\# 2$ can continue its oil production for some more few years after 4500 days due to the minimal reduction in the slope of oil recovery curve. Using Fig. 7, it can be estimated by extrapolation that the amount of oil recovery for high-salinity water flooding does not exceed $51 \%$ after many years of injection. However, the difference in oil recovery between each of three models and HSW flooding increases more and more over time, which reveals that the efficiency of LSW flooding rises after many years from the beginning of the injection; hence, LSW flooding is only useful for the secondary or tertiary stage of production. The amount of recovery enhancement in this study is consistent with previous researches, although some published data indicated even higher oil recovery within LSW flooding (Jerauld et al. 2006b; Kim and Lee 2017; Lager et al. 2008a; Omekeh et al. 2013; Shojaei et al. 2015).

Well water cut for three models and high-salinity water flooding are also shown in Fig. 7. High-salinity water cut reached to 0.965 at 4500 days after brine injection, also the water cut for three models were lower than the highsalinity water flooding at the end of the simulation and were equal to $0.884,0.882$, and 0.896 , respectively. These values demonstrate that low-salinity water flooding has more advantageous over high-salinity water flooding; for example, if the maximum economical produced water cut is considered to be 0.85 (as route value in the petroleum industry), high-salinity water flooding can produce up to 1780 days $(0.55 \mathrm{PV})$, while three other models can continue their production $1706(0.53 \mathrm{PV}), 1892(0.60 \mathrm{PV})$, and 143 (0.044 PV) days more than the high-salinity water flooding, respectively. Therefore, by using low-salinity water flooding with various salinity threshold ranges, the corresponding oil recovery can be improved approximately $11.831 \%$, $14.672 \%$ and $0.67 \%$ for each model. Moreover, this figure argues that the slope of increasing water cut is reduced during low-salinity water flooding; as a result, we can continue oil production for many years after water breakthrough. Figure 7 also reveals that the narrow salinity threshold range was less effective than the wide salinity threshold range. Furthermore, it is obvious that the reduction of well water cut is more pronounced at the end of the simulation. The difference between the values of well water cut for three models in comparison to high-salinity water flooding have decreased by expanding the salinity threshold range.

The average field pressure of the oil phase for three models and high-salinity water flooding model are plotted versus time in Fig. 8. The behavior of average field oil phase pressure is clearly stranger than two previous parameters to be interpreted. Based on this figure, it can be implied that the average field oil phase pressure for LSW flooding is lower than HSW flooding after breakthrough time due to higher oil production rate. As accordingly expected, this value for model\#2 is lower than model\#1 followed by model\#3 and HSW model. Atthawutthisim (2012) reported that the average field pressure for LSW flooding is slightly lower than HSW flooding due to the increase in oil production rate during LSW process, which leads to a decrease in average reservoir pressure. We can also justify this issue by considering the lower fluid flow resistivity and higher oil relative permeability during LSW flooding, which results in easier oil production under a lower pressure gradient.

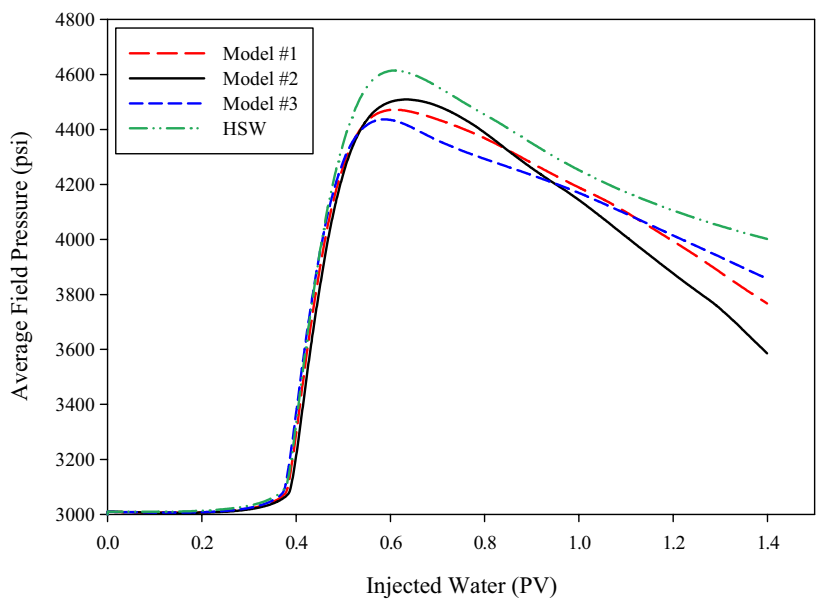

Fig. 8 Effect of salinity threshold and weighting coefficient on average field pressure

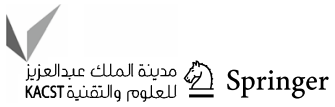


Figure 9 illustrates different water saturation distribution maps calculated for HSW and LSW flooding in model\#2 at various simulation times. Both HSW and LSW are injected from injection wells located at each corner and displace the oil through a production well located at the center of the reservoir model. Therefore, the water saturation has the highest value at each corner and it gradually decreases as we move to the production well for all models at each simulation time. However, the amount of oil saturation reduction is more pronounced for LSW flooding compared to HSW flooding at a specific simulation time. It confirms that the oil is more displaced during LSW flooding. Furthermore, the creation of an oil bank during the LSW flooding clearly appears in Fig. 9, especially at the simulation time of 300 and 1000 days (see the light blue region shown in these figures), while there is no oil bank in the HSW flooding.

The results of this section claim that determination of salinity threshold range is severely crucial before implementation of low-salinity water injection in field scale since the wrong prediction of this parameter leads to an inaccurate estimation of oil recovery at large reservoir scale. These results also assert that wider salinity threshold ranges have certainly more benefits than narrower salinity threshold ranges. Whereas it is notable that low-salinity water flooding in a real reservoir takes more time to affect the reservoir performance. Although the oil recovery improvement during LSW flooding is lower than other methods such as miscible flooding, ASP flooding, etc., it is considered as one of the most economical EOR methods.

In order to ensure that all the results obtained by developed code have consistency with each other, the results of well water cut, field oil recovery, and average field pressure are plotted in the same graph as can be found in Fig. 10. The concentration of produced water is basically expected to decrease over time after breakthrough due to reaching the low concentration water into the production well. Same as the salinity of the produced water at the production well, the well water cut must suddenly increase from zero value coincident with the deviation of field oil recovery from a straight line versus simulation time. The breakthrough time determined by using the aforementioned curves can be represented by a specific time that happened at 1241 days (0.389 PV).

\section{Sensitivity analysis on the obtained results}

In order to prove that the effect of numerical dispersion is minimized in our simulation study, a sensitivity analysis is performed as shown in Fig. 11. Since the time step in this study is chosen small enough to prevent the numerical dispersion (less than a day), the sensitivity analysis is just performed on the effect of grid block size. For this purpose, some low-salinity water flooding simulations were conducted using relative permeability data of model\#2. The porosity and horizontal absolute permeability were considered to be constant as 0.17 and $250 \mathrm{mD}$ (one-tenth of this amount in the vertical direction), respectively, while other reservoir characteristics remained the same. The reservoir was allowed to have only three layers in all runs. An accurate exploration in Fig. 11 reveals that there is no changing in recovery curve by increasing the reservoir grid block number till 39 grids in $x$ and $y$ directions. Therefore, we can make sure that the recovery curve and consequently other results presented in this study are independent of the reservoir gridding.

\section{Effect of aging time in wettability alteration process on oil recovery}

As mentioned earlier, none of the researchers have considered the effect of aging time in their simulations. However, this matter is undertaken perfectly in the present study. The implementation procedure is completely explained in "Effect of aging time in wettability alteration process on oil recovery". By accepting this procedure, the general model was run with consideration of 4 days and 10 days aging time. Figure 12 presents the value of oil recovery for three models which are run with the aging time of 0,4 , and 10 days, respectively. Since the aging time is negligible in comparison to the total simulation time, three oil recovery curves are similar to each other; however, the exact values of oil recovery, water cut, and average field pressure in three models are different as listed in Table 4. As can be seen, the variation between three models is not significant. For instance, the well water cut is approximately equal for all three models and it is a little bit larger for the model with 10 days aging time because wettability alteration occurs later. The possible reason for this result may be attributed to the large simulation time which leads the effect of delay in wettability alteration process to be disappeared. The second reason would also be related to the large reservoir volume or oil production rate which is not high enough. It is expected that if the reservoir has a lower pore volume, the effect of aging time could not be negligible.

To summarize the results of filed scale simulation, the aging time has a less influence on oil recovery, well water cut and average field pressure in field scale; therefore, recently related studies such as Mahani et al. (2011) is practical only for laboratory experiments. Due to a large production time period, the aging time effect is diminished in filed scale modeling, which shows the fact that this effect should only be considered in core flood simulation or in the small-scale simulation. Moreover, at high oil production rate or low distance between production and injection well, this effect can be greater in comparison with a real reservoir situation. Therefore, the consideration of this phenomenon is not 
Fig. 9 Water saturation distribution for HSW flooding (left side) and model\#2 (right side)

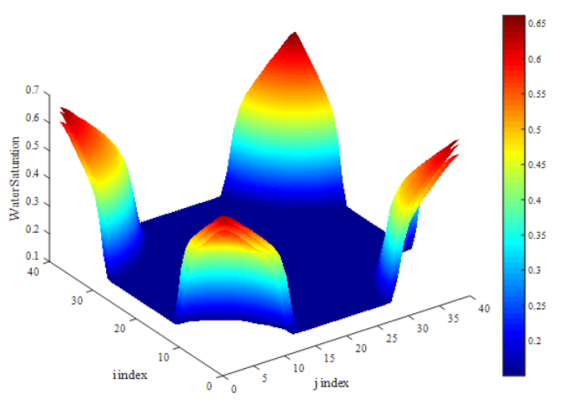

Injected water $=0.0933$ PV (300 days $)$

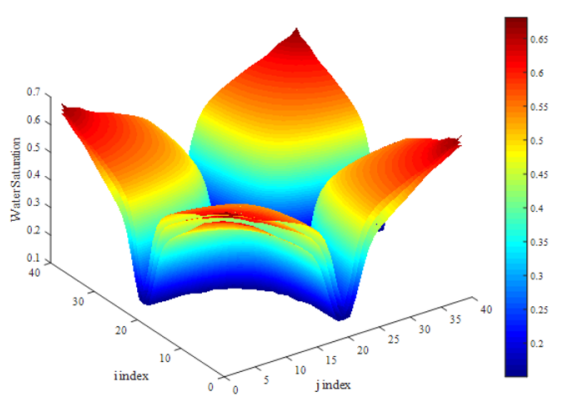

Injected water $=0.311 \mathrm{PV}(1000$ days $)$

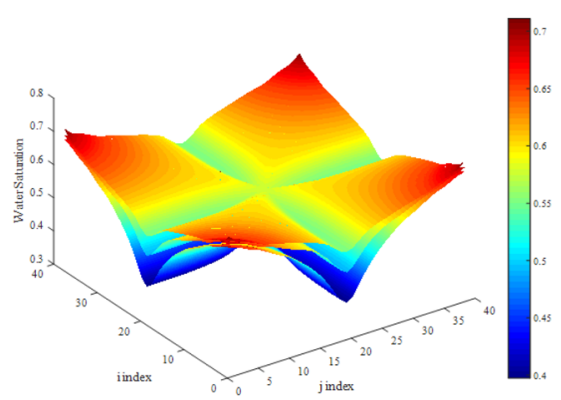

Injected water $=0.773$ PV (2500 days)

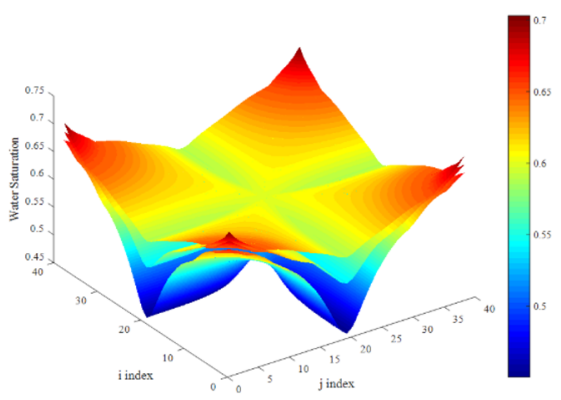

Injected water $=1.40 \mathrm{PV}(4500$ days $)$

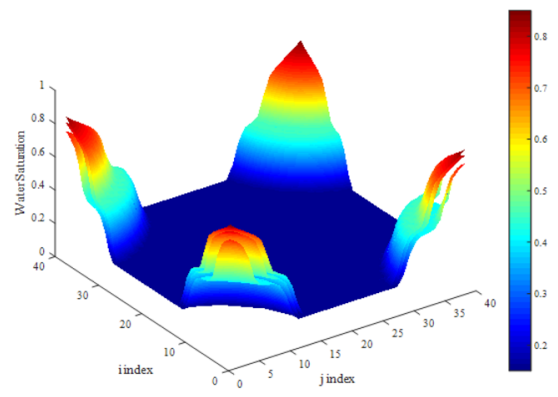

Injected water $=0.0933 \mathrm{PV}(300$ days $)$

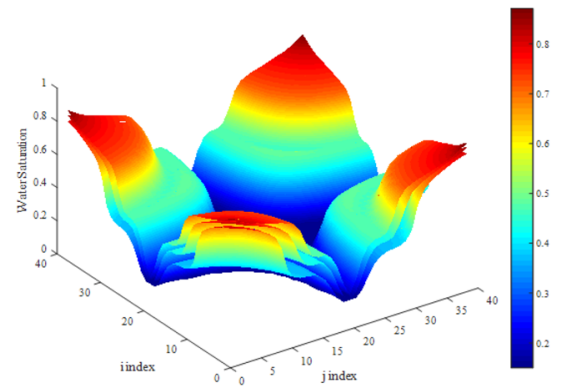

Injected water $=0.311 \mathrm{PV}(1000$ days $)$

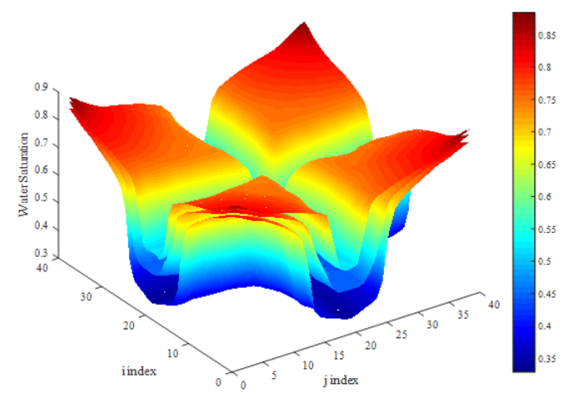

Injected water $=0.773 \mathrm{PV}$ (2500 days $)$

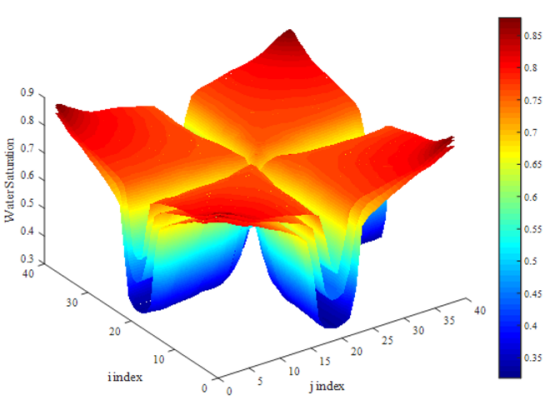

Injected water $=1.40 \mathrm{PV}$ (4500 days $)$ 


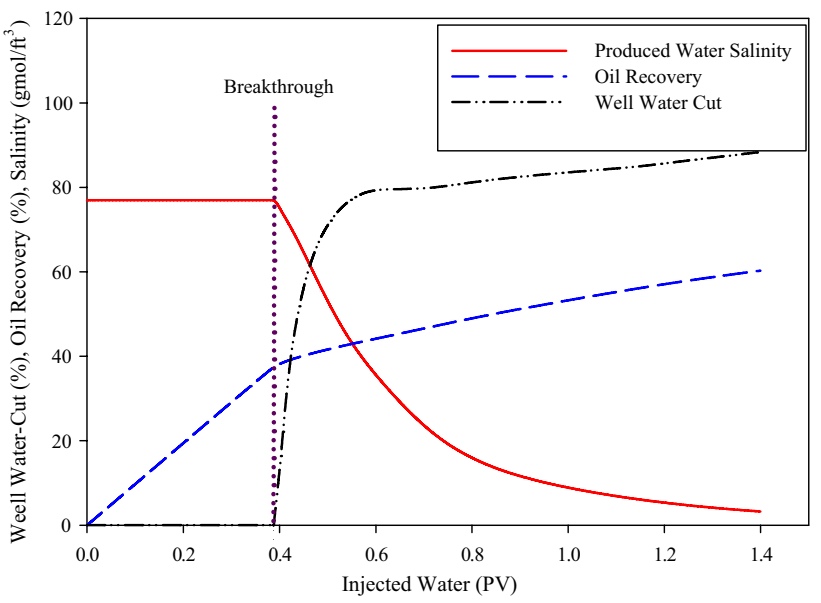

Fig. 10 Well water cut, oil recovery and average field pressure versus time for model \#2

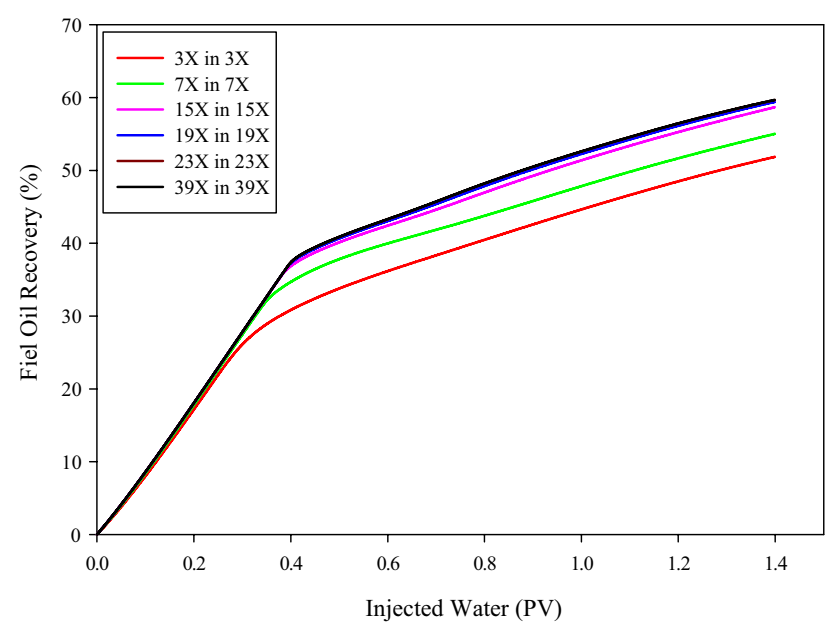

Fig. 11 The sensitivity analysis on the field oil recovery with various grid block size

essential for the field-scale study. It is admittedly accepted that aging time has an adverse effect on improved oil recovery due to postponing wettability alteration process.

An insight into the effect of aging time on the performance of LSW flooding can be precisely accomplished by a fine-grid 1D reservoir simulation. As we have claimed by analyzing the results of field-scale simulations, the effect of aging time can be more pronounced in a core flooding or a small-scale simulation; hence, a small fine-grid 1D model is employed here to nicely prove our assertion. This model contains 1000 grid blocks with the size of $0.15 \mathrm{ft}$ in $x$-direction and 1 grid block with the size of $1 \mathrm{ft}$ in $y$ - and $z$-directions and totally has two wells (one production well and one injection well) located at the each end with the well radius of $0.05 \mathrm{ft}$ in the $1 \mathrm{D}$ model, where the production well operates at a constant bottom-hole pressure of 2700 psi and injection

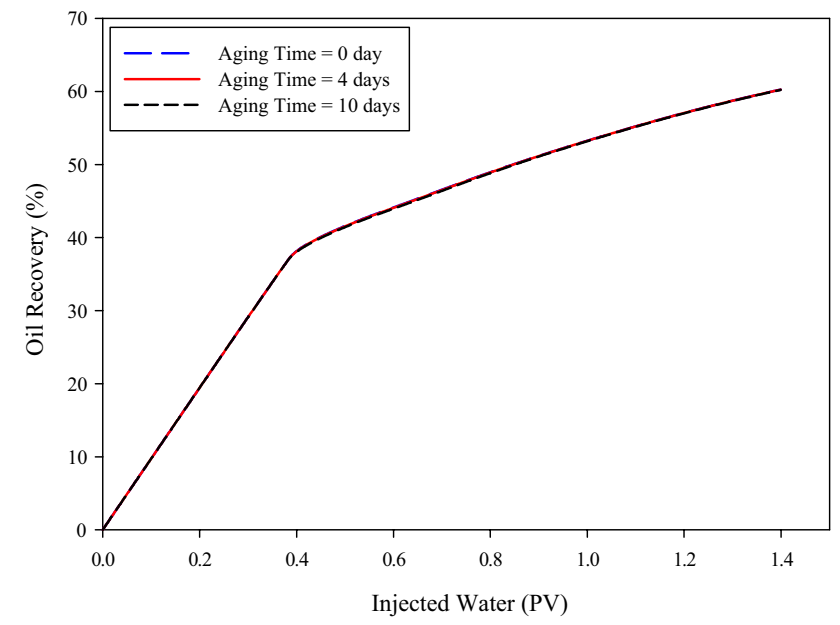

Fig. 12 Effect of aging time in wettability alteration process on LSW oil recovery

rate is kept constant at $0.1 \mathrm{bbl} / \mathrm{day}$. It should be noted that other fluid/rock properties are same as model\#2 which is described earlier. Like the field-scale reservoir simulation, the injected brine salinity remains constant at $500 \mathrm{ppm}$ and the aging times of 0,4 , and 10 days are considered to assess their effects. Although the simulation time during the fieldscale model was 4500 days, equal to injection of $1.4 \mathrm{PV}$ of water, this $1 \mathrm{D}$ simulation only took 50 days, but we need to keep in mind that the total volume of injected water in PV unit is approximately same as the field-scale simulation. By this way, the aging time should be comparable with the water flooding duration.

In order to analyze the results of this fine-grid 1D simulation, the saturation profile within the system at various times (or volume of injected water in PV) along with the well water cut, average reservoir pressure, and oil recovery are examined. Figure 13a compares the water saturation within the model in absence and presence of aging time. The shape of saturation profile captured in these models is completely different, where the development of an oil bank is obvious in the model with the aging time of 10 days, due to the delay in wettability alteration process. Generally, there are two different frontal advance equations in LSW flooding, one for low-salinity condition and another one for high-salinity condition, which results in forming an oil bank in the system. Basically, two different sharp fronts can be seen in the model with no aging time, while an oil bank is developed gradually in the model with the aging time of 10 days which results in a delay in the oil production. The production well water cut is also plotted over time for three models in Fig. 13b which is completely consistent with the results of the water saturation profile. The gradual establishment of the oil bank in models considering the aging times of 4 and 10 days leads the water cut to decrease after reaching the breakthrough 
and again increases after a while (see a significant drop from 0.93 to 0.36 in the model considering 10 days aging time). In contrast to these models, this phenomenon is masked if no aging time is assumed.

The value of oil recovery and average reservoir pressure are also demonstrated in Fig. 14a, b for these models. The trend of the recovery curve as well as the water cut curve obtained for the model considering no aging time are same as the results of secondary recovery of LSW flooding, although this trend in the model considering the aging time is mostly similar to the results of tertiary recovery of LSW flooding (Bartels et al. 2019), especially when we assume that the wettability alteration process takes 10 days to happen. Contrarily to the reservoir filed scale simulation which indicated no variation in the oil recovery curve or even a negligible variation in water cut during 4500 days of injection, the 1D small-scale modeling clearly indicates that the meaningful difference can be acquired, if the effect of aging time is taken into account within reservoir simulation.

According to Fig. 14b, lower reservoir pressure is obtained for the model with no aging time due to the higher oil production rate or higher depletion rate of reservoir. Accordingly, we expect that the model with 10 days aging time must have a higher filed pressure which is depicted in Fig. 14b. It should be pointed out that after injection of a large volume of low-salinity water, the wettability alteration would be completely expanded over the reservoir which resulted in a very close value of oil recovery, well water cut and average filed pressure of different models. This matter is completely consistent with the results of field-scale simulation when the aging time (10 days) can be overlooked in compared to the injection time (4500 days).

Table 7 Values of constant coefficients in brine compressibility equation (Eq. (16))

\begin{tabular}{llll}
\hline Coefficient & Value & Coefficient & Value \\
\hline$E_{w(1)}(T)$ & 4.221 & $E_{C_{m}(1)}(T)$ & 0 \\
$E_{w(2)}(T)$ & -3.478 & $E_{C_{m}(2)}(T)$ & 0 \\
$E_{w(3)}(T)$ & 6.221 & $E_{C_{m}(3)}(T)$ & 0.1353 \\
$E_{w(4)}(T)$ & 0.5182 & $E_{C_{m}(4)}(T)$ & 0 \\
$E_{w(5)}(T)$ & -0.4405 & $E_{C_{m}(5)}(T)$ & 0 \\
$F_{w(1)}(T)$ & -11.403 & $F_{C_{m}, 3 / 2(1)}(T)$ & -1.409 \\
$F_{w(2)}(T)$ & 29.932 & $F_{C_{\mathrm{m}}, 3 / 2(2)}(T)$ & -0.361 \\
$F_{w(3)}(T)$ & 27.952 & $F_{C_{m}, 3 / 2(3)}(T)$ & -0.2532 \\
$F_{w(4)}(T)$ & 0.20684 & $F_{C_{m}, 3 / 2(4)}(T)$ & 00 \\
$F_{w(5)}(T)$ & 0.3768 & $F_{C_{m}, 3 / 2(5)}(T)$ & 9.216 \\
$F_{C_{m}, 1(1)}(T)$ & 0 & $F_{C_{m}, 1 / 2(1)}(T)$ & -0.1127 \\
$F_{C_{m}, 1(2)}(T)$ & 5.614 & $F_{C_{m}, 1 / 2(2)}(T)$ & 0.2047 \\
$F_{C_{m}, 1(3)}(T)$ & 4.6782 & $F_{C_{m}, 1 / 2(3)}(T)$ & -0.0452 \\
$F_{C_{m}, 1(4)}(T)$ & -0.307 & $F_{C_{m}, 1 / 2(4)}(T)$ & 0 \\
$F_{C_{m}, 1(5)}(T)$ & 2.6069 & $F_{C_{m}, 1 / 2(5)}(T)$ & 0 \\
\hline
\end{tabular}

Table 8 Values of constant coefficients in brine viscosity equation (Eq. 31)

\begin{tabular}{llll}
\hline Coefficient & Value & Coefficient & Value \\
\hline$\alpha_{1}$ & 1.2378 & $a_{1}$ & $3.324 \times 10^{-2}$ \\
$\alpha_{2}$ & $-1.303 \times 10^{-3}$ & $a_{2}$ & $3.624 \times 10^{-3}$ \\
$\alpha_{3}$ & $3.06 \times 10^{-6}$ & $a_{3}$ & $-1.879 \times 10^{-4}$ \\
$\alpha_{4}$ & $2.55 \times 10^{-8}$ & $\beta_{0}$ & -1.297 \\
$\gamma_{0}$ & 0.545 & $\beta_{1}$ & $5.74 \times 10^{-2}$ \\
$\gamma_{1}$ & $2.8 \times 10^{-3}$ & $\beta_{2}$ & $-6.97 \times 10^{-4}$ \\
$b_{1}$ & $-3.96 \times 10^{-2}$ & $\beta_{3}$ & $4.47 \times 10^{-6}$ \\
$b_{2}$ & $1.02 \times 10^{-2}$ & $\beta_{4}$ & $-1.05 \times 10^{-8}$ \\
$b_{3}$ & $7.02 \times 10^{-4}$ & $\beta_{1}^{*}$ & 2.50 \\
$m_{1}$ & 6.044 & $\beta_{2}^{*}$ & -2.00 \\
$m_{2}$ & $2.8 \times 10^{-3}$ & $\beta_{3}^{*}$ & 0.50 \\
$m_{3}$ & $3.6 \times 10^{-5}$ & $\mu_{\mathrm{w}}^{0}\left(20{ }^{\circ} \mathrm{C}\right)$ & $1.0020 \mathrm{cp}$ \\
\hline
\end{tabular}

\section{Effect of injection brine salinity selection along with salinity threshold range on oil recovery}

The values of oil recovery for three salinity threshold ranges as a function of injection brine salinity are presented in Fig. 15. This figure is drawn in semi-logarithmic scale for more clarification. According to this figure, at a given injection brine salinity, oil recovery for model\#2 is significantly higher than two other models and for model\#1 is also higher than model\#3. Furthermore, by decreasing injection brine salinity, oil recovery is gradually increased for all models, although this increase is not equal for each model. For instance, at injection brine salinity between 7000 and $10,000 \mathrm{ppm}$, there is a significant slope reduction for model\#2 in comparison to the other models. In contrast to model\#2, a sharp jump in oil recovery occurs between 750 and $2000 \mathrm{ppm}$ for model\#1. Therefore, the slope of these three curves reveals different behavior versus injection brine salinity; however, all three curves have an inverse "S" shape in injection brine salinity ranges of 200-20,000 ppm. Due to the slope variation within the salinity ranges of 200-20,000 ppm, it can be implied that injection brine salinity reduction does not have the same effect on oil recovery within a particular salinity threshold range. This figure argues that the remarkable effect of injection brine salinity reduction occurs in a specific injection brine salinity, which has a maximum slope of the oil recovery curve. This point suggests that by a slight decrease in injection brine salinity, oil recovery can be greatly increased. However, at higher or lower brine concentration than this optimum point, the slope of the curve would be declined.

The derivative of oil recovery versus injection brine salinity is also plotted in Fig. 15. The maximum slope of oil recovery curve happens in a specific value of injection brine salinity for various brine salinity threshold ranges. 


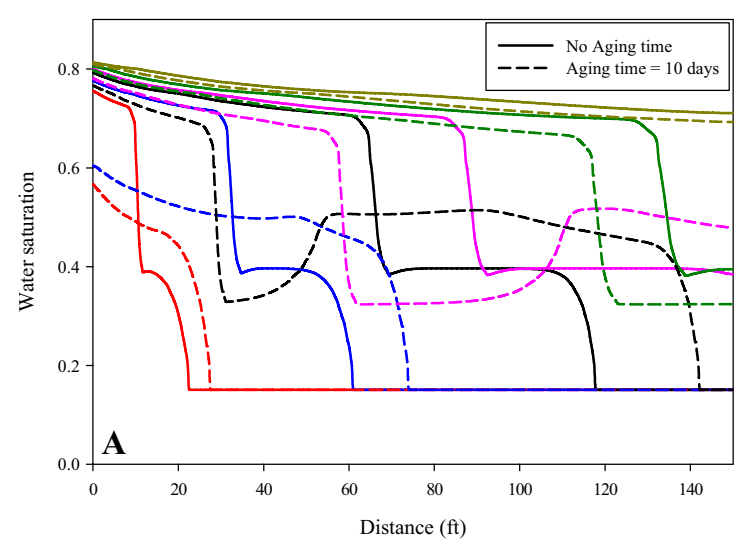

Fig. 13 a The water saturation profile during LSW flooding with the aging time of 10 days and without aging time [red: 0.056 PV (2.5 days), blue: $0.165 \mathrm{PV}$ (7.5 days), black: $0.33 \mathrm{PV}$ (15 days), pink:

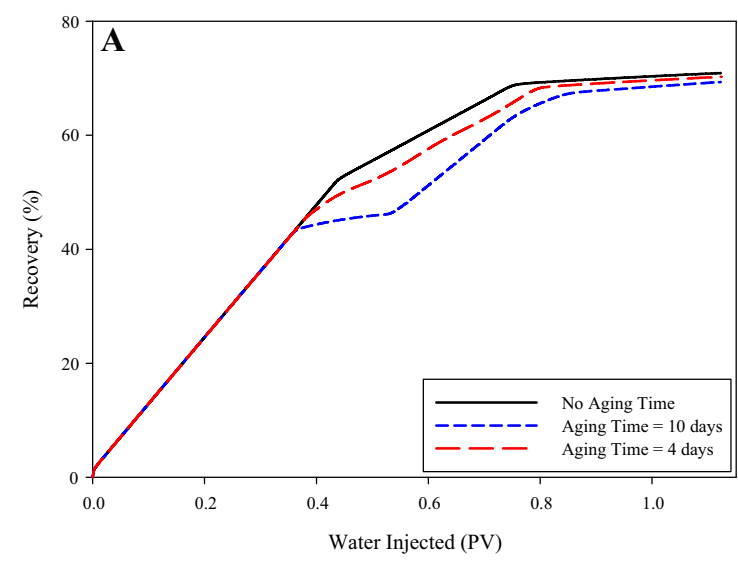

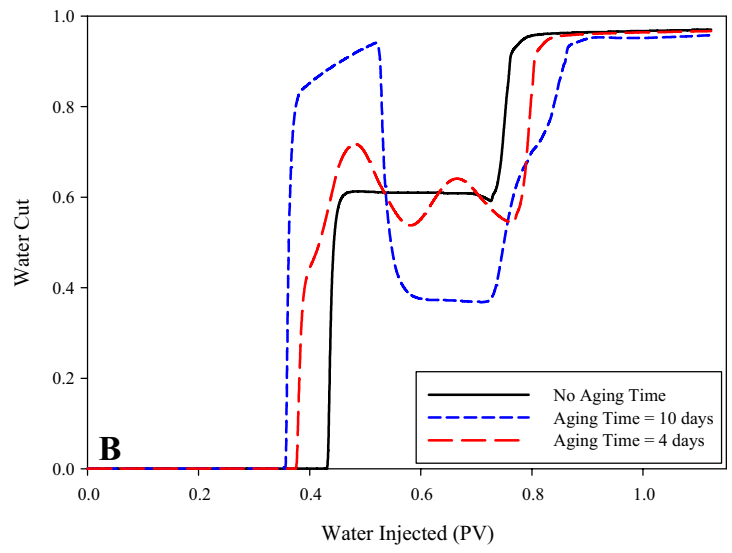

0.44 PV (20 days), green: 0.66 PV (30 days), dark yellow: 1.1 PV (50 days)], and $\mathbf{b}$ well water cut of model considering the aging time of 0 , 4 , and 10 days

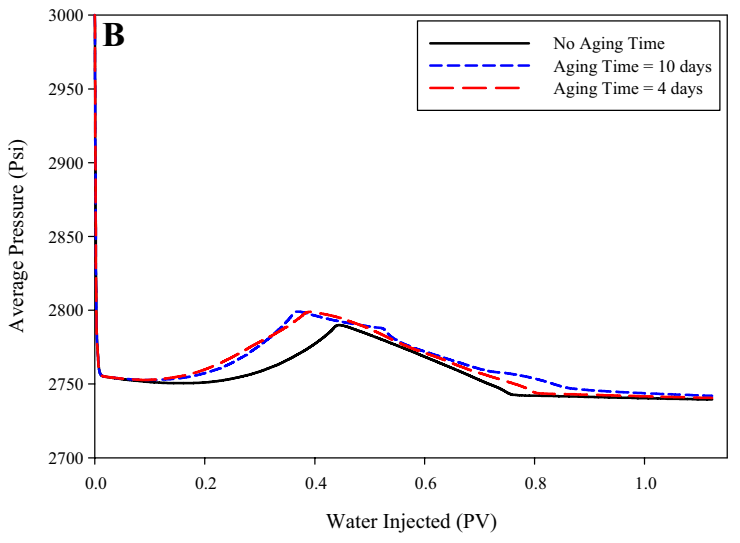

Fig. 14 a The oil recovery, and $\mathbf{b}$ well water cut of the model considering the aging time of 0,4 , and 10 days during LSW flooding versus PV of water injected

For model\#1, model\#2, and model\#3, this point appears at the injection brine salinity equal to $3400 \mathrm{ppm}, 5000 \mathrm{ppm}$, and $1200 \mathrm{ppm}$, respectively. This figure also shows that the narrow brine salinity threshold range is less sensitive to injection brine salinity compared to a wide brine salinity threshold range. Therefore, both the brine salinity range and the injection brine salinity have important effects on LSW flooding performance.

Figure 16 illustrates production well water cut versus injection brine salinity for three models. As it is shown in this figure, injection brine salinity reduction has a considerable effect on the reduction of water cut in all models. However, similar to Fig. 15, three curves have "S" shape which means that the significant water cut reduction occurs in a particular value of injection brine salinity. Thus, it is not economical to reduce the injection brine salinity to very low values such as 200 ppm or even lower salinities.
The results claim that suitable injection brine salinity is proportional to the point which has the highest slope in the well water cut curve. As shown in Fig. 16, decreasing the injection brine salinity leads to the decrease in average field pressure for all three models. Moreover, the value of average field oil phase pressure is lower for model\#2 in comparison to model\#1 followed by model\#3 which is related to the earlier wettability alteration for model\#2. In this case, the oil phase relative permeability increases and there would be lower fluid flow resistivity for production. Therefore, total liquids production would be increased and the reservoir depletion happens rapidly during the production. Although some inconsistency can be observed in average field pressure data with oil production rate at a certain range of brine salinity, it would be related to the effect of other parameters such as reservoir geometry or weighting factors as well as the oil production rate. Figure 16 also 

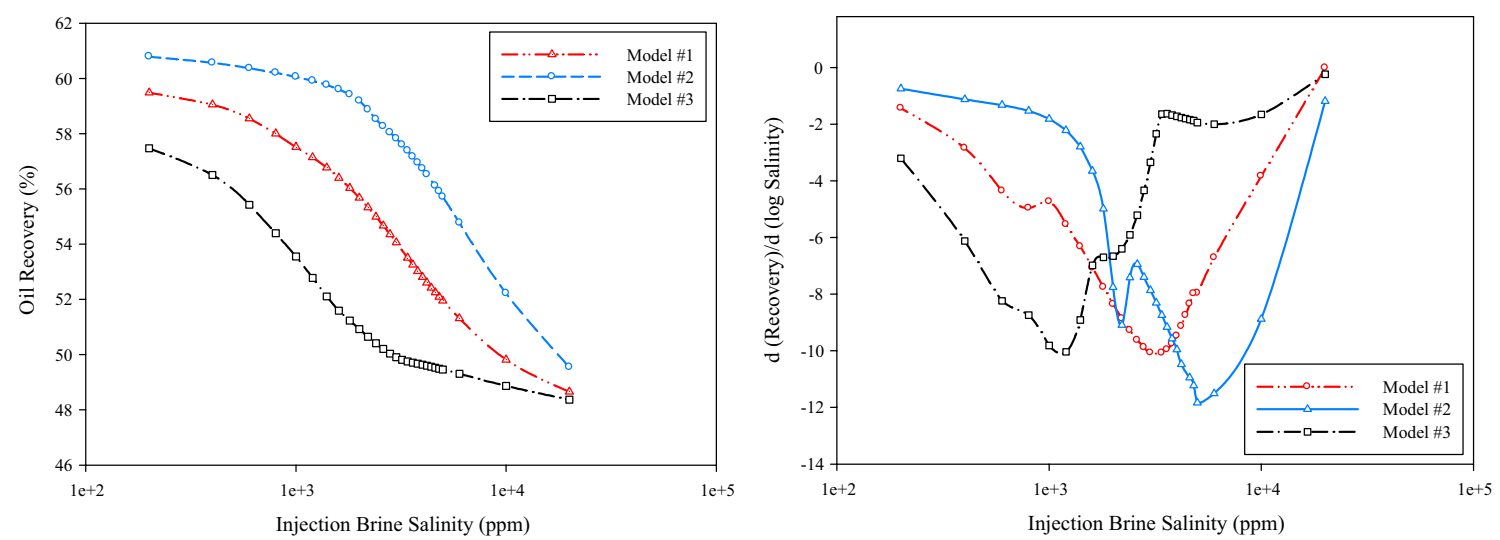

Fig. 15 Effect of injection brine salinity on the oil recovery (left side) and its derivative regarding injection brine salinity (right side) in various salinity threshold ranges

asserts that a wide brine salinity threshold range is less sensitive to lower values of injection brine salinity than a narrow brine salinity threshold range.

\section{Conclusion}

The two-phase low-salinity water flooding (LSW) was simulated in a three-dimensional reservoir model by a code developed in MATLAB computer programing software using fully implicit approach. A base case model was used for model validation and its results including the average filed pressure, oil recovery and production well water cut were consistent with a petroleum engineering commercial software results, demonstrating the programming code accuracy. There was also an insight into the effect of brine salinity threshold, aging time and injection brine salinity selection using a general model. The results of the brine salinity threshold range showed that a wide brine salinity threshold range has more advantages over a narrow range due to earlier wettability alteration during LSW flooding, which leads to lower oil flow resistance and higher oil production rate. The aging time which had been experimentally studied by some researchers showed little influence for a large period of production time in a real reservoir, although the fine-grid 1D simulation on a small sample proves that the consideration of aging time could be more essential in core flooding experiments or small-scale reservoirs and not in the field-scale simulations, due to the comparable aging time with the implementation time of flooding. The results of injection brine salinity selection suggest that the reduction of injection brine salinity causes an improvement in oil recovery and LSW flooding performance; however, the significant impact occurs only at a particular injection brine salinity within the given brine salinity threshold ranges. The optimum injection brine salinities were found to be $3400 \mathrm{ppm}$, $5000 \mathrm{ppm}$ and $1200 \mathrm{ppm}$ in the models involved in this study.

Open Access This article is distributed under the terms of the Creative Commons Attribution 4.0 International License (http://creativeco
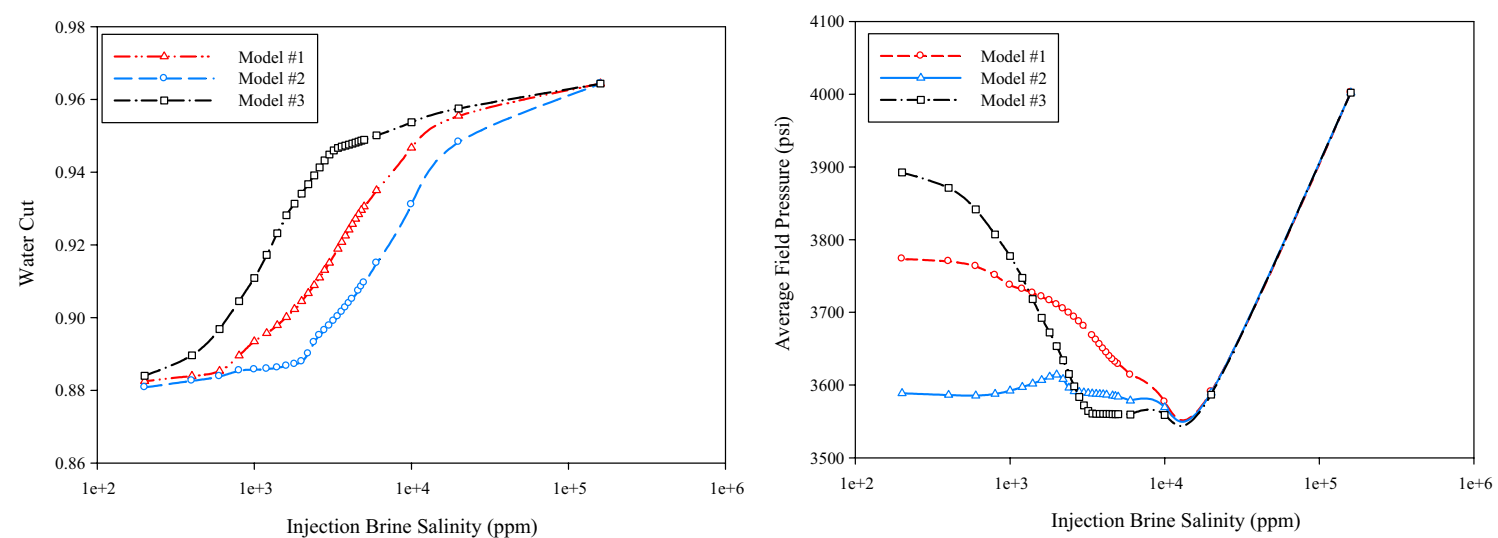

Fig. 16 Effect of injection brine salinity on production well water cut and average field pressure in various salinity threshold ranges 
mmons.org/licenses/by/4.0/), which permits unrestricted use, distribution, and reproduction in any medium, provided you give appropriate credit to the original author(s) and the source, provide a link to the Creative Commons license, and indicate if changes were made.

\section{Appendix 1: Estimation of brine physical properties}

Based on Spivey et al. (2004) correlation, Eq. (13) can be used to evaluate water density at $70 \mathrm{Mpa}$. Then, this equation is combined with some parameters to develop a new correlation for brine density at $70 \mathrm{Mpa}$ as a function of temperature and brine salinity as is stated in Eq. (14).

$$
\begin{gathered}
\rho_{\mathrm{w} 0}(T)=\frac{D_{\mathrm{w} 1}(T / 100)^{2}+D_{\mathrm{w} 2}(T / 100)+D_{\mathrm{w} 3}}{D_{\mathrm{w} 4}(T / 100)^{2}+D_{\mathrm{w} 5}(T / 100)+1} \\
\rho_{\mathrm{b} 0}=\rho_{\mathrm{w} 0}+D_{C_{\mathrm{m}}, 2}(T) C_{\mathrm{m}}^{2}+D_{C_{\mathrm{m}}, 3 / 2}(T) C_{\mathrm{m}}^{3 / 2} \\
+D_{C_{\mathrm{m}}, 1}(T) C_{\mathrm{m}}+D_{C_{\mathrm{m}}, 1 / 2}(T) C_{\mathrm{m}}^{1 / 2}
\end{gathered}
$$

The constants of $D_{\mathrm{w} 1}$ through $D_{\mathrm{w} 5}$ in Eq. (13) are summarized in Table 5. Moreover, the temperature-dependent parameters (given in Table 6) in Eq. (14) (such as $D_{C_{\mathrm{m}}, 2}$ ) can be calculated by Eq. (15):

$\alpha(T)=\frac{\alpha_{1}(T / 100)^{2}+\alpha_{2}(T / 100)+\alpha_{3}}{\alpha_{4}(T / 100)^{2}+\alpha_{5}(T / 100)+1}$.

Brine compressibility is correlated using Eq. (16) as a function of pressure, temperature, and brine salinity:

$$
\begin{aligned}
c_{\mathrm{b}}\left(p, T, C_{\mathrm{m}}\right)= & \frac{1 / p_{0}}{E_{\mathrm{b}}\left(T, C_{\mathrm{m}}\right)\left(p / p_{0}\right)+F_{\mathrm{b}}\left(T, C_{\mathrm{m}}\right)}, \\
E_{\mathrm{b}}\left(T, C_{\mathrm{m}}\right)= & E_{\mathrm{w}}(T)+E_{C_{\mathrm{m}}}(T) C_{\mathrm{m}}, \\
F_{\mathrm{b}}\left(T, C_{\mathrm{m}}\right)= & F_{\mathrm{w}}(T)+F_{C_{\mathrm{m}}, 3 / 2}(T) C_{\mathrm{m}}^{3 / 2} \\
& +F_{C_{\mathrm{m}}, 1}(T) C_{\mathrm{m}}+F_{C_{\mathrm{m}}, 1 / 2}(T) C_{\mathrm{m}}^{1 / 2},
\end{aligned}
$$

$I_{\mathrm{b}}\left(p, T, C_{\mathrm{m}}\right)=\frac{1}{E_{\mathrm{b}}\left(T, C_{\mathrm{m}}\right)} \ln \left|E_{\mathrm{b}}\left(T, C_{\mathrm{m}}\right)\left(p / p_{0}\right)+F_{\mathrm{b}}\left(T, C_{\mathrm{m}}\right)\right|$.

Table 4 Comparison of oil recovery, average field pressure and well water cut for various aging times at final simulation time
Table 5 Values of constant coefficients in pure water density equation (Eq. (13)) at reference pressure

\begin{tabular}{lc}
\hline Coefficient & Value \\
\hline$D_{\mathrm{w} 1}(T)$ & -0.127213 \\
$D_{\mathrm{w} 2}(T)$ & 0.645486 \\
$D_{\mathrm{w} 3}(T)$ & 1.03265 \\
$D_{\mathrm{w} 4}(T)$ & -0.070291 \\
$D_{\mathrm{w} 5}(T)$ & 0.639589
\end{tabular}

Table 6 Values of constant coefficients in brine density equation (Eq. (14)) at reference pressure

\begin{tabular}{llll}
\hline Coefficient & Value & Coefficient & Value \\
\hline$D_{C_{m}, 2(1)}(T)$ & $-7.925 \times 10^{-5}$ & $D_{C_{m}, 1(1)}(T)$ & $-7.6402 \times 10^{-3}$ \\
$D_{C_{m}, 2(2)}(T)$ & $-1.93 \times 10^{-6}$ & $D_{C_{m}, 1(2)}(T)$ & $3.6963 \times 10^{-2}$ \\
$D_{C_{m}, 2(3)}(T)$ & $-3.4254 \times 10^{-4}$ & $D_{C_{m}, 1(3)}(T)$ & $4.36083 \times 10^{-5}$ \\
$D_{C_{m}, 2(4)}(T)$ & 0 & $D_{C_{m}, 1(4)}(T)$ & $-3.33661 \times 10^{-1}$ \\
$D_{C_{m}, 2(5)}(T)$ & 0 & $D_{C_{m}, 1(5)}(T)$ & 1.185685 \\
$D_{C_{m}, 3 / 2(1)}(T)$ & $1.0998 \times 10^{-3}$ & $D_{C_{m}, 1 / 2(1)}(T)$ & $3.746 \times 10^{-4}$ \\
$D_{C_{m}, 3 / 2(2)}(T)$ & $-2.8755 \times 10^{-3}$ & $D_{C_{m}, 1 / 2(2)}(T)$ & $-3.328 \times 10^{-4}$ \\
$D_{C_{m}, 3 / 2(3)}(T)$ & $-3.5819 \times 10^{-3}$ & $D_{C_{m}, 1 / 2(3)}(T)$ & $-3.346 \times 10^{-4}$ \\
$D_{C_{m}, 3 / 2(4)}(T)$ & $-7.2877 \times 10^{-1}$ & $D_{C_{m}, 1 / 2(4)}(T)$ & 0 \\
$D_{C_{m}, 3 / 2(5)}(T)$ & 1.92016 & $D_{C_{m}, 1 / 2(5)}(T)$ & 0 \\
\hline
\end{tabular}

By combining Eqs. (14)-(19), brine density at any given temperature, pressure and salinity can be calculated in the form of Eq. (20).

$\rho_{\mathrm{b}}\left(p, T, C_{\mathrm{m}}\right)=\rho_{\mathrm{b} 0}\left(T, C_{\mathrm{m}}\right) \exp \left[I_{\mathrm{b}}\left(p, T, C_{\mathrm{m}}\right)-I_{\mathrm{b}}\left(p_{0}, T, C_{\mathrm{m}}\right)\right]$.

In the above equation, $p_{0}$ is reference pressure equal to $70 \mathrm{Mpa}, p$ is the water pressure in $\mathrm{MPa}, T$ is the temperature in ${ }^{\circ} \mathrm{C}$ and $C_{\mathrm{m}}$ is brine salinity in $\mathrm{mol} / \mathrm{Kg} \mathrm{H}_{2} \mathrm{O}$. The density is calculated by this equation is in $\mathrm{g} / \mathrm{cm}^{3}$. All constant such as $E_{\mathrm{w}}, F_{\mathrm{w}}$, etc., are summarized in Table 7.

Brine formation volume factor can be easily defined by dividing brine density at standard condition into brine density at reservoir condition. The temperature and pressure at standard condition are equal to $15^{\circ} \mathrm{F}$ and 14.696 psi, respectively. By using Eq. (21), the brine formation volume factor is calculated:

$$
B_{\mathrm{w}}=\frac{\rho_{\mathrm{b}}^{\mathrm{st}}\left(p=14.696 \mathrm{psi}, T=15^{\circ} \mathrm{F}, C_{\mathrm{m}}\right)}{\rho_{\mathrm{b}}\left(p, T, C_{\mathrm{m}}\right)} .
$$

\begin{tabular}{lccc}
\hline Parameters & Aging time $=0$ day & Aging time=4 days & $\begin{array}{l}\text { Aging } \\
\text { time }=10 \\
\text { days }\end{array}$ \\
\hline Oil recovery $(\%)$ & 60.3355 & 60.3001 & 60.2698 \\
Well water cut & 0.8837 & 0.8840 & 0.8846 \\
Average field pressure (psi) & 3584.34 & 3585.22 & 3587.91 \\
\hline
\end{tabular}


To calculate the dynamic viscosity of brine, following empirical correlation are employed, based on what was developed by Kestin et al. (1981).

$$
\log _{10}\left[\mu_{\mathrm{w}}^{0}\left(T, C_{\mathrm{m}}\right) / \mu_{\mathrm{w}}^{0}\left(20^{\circ} \mathrm{C}\right)\right]=\left\{\sum_{i=1}^{4} \alpha_{i}[(20-T)]^{i}\right\} /[96+T]
$$

$A(m)=\sum_{i=1}^{3} a_{i}\left(C_{\mathrm{m}}\right)^{i}$

$B(m)=\sum_{i=1}^{3} b_{i}\left(C_{\mathrm{m}}\right)^{i}$

$\log _{10}\left[\mu_{\mathrm{w}}^{0}\left(T, C_{\mathrm{m}}\right) / \mu_{\mathrm{w}}^{0}(T)\right]=A(m)+B(m) \log _{10}\left[\mu_{\mathrm{w}}^{0}(T) / \mu_{\mathrm{w}}^{0}\left(20{ }^{\circ} \mathrm{C}\right)\right]$

$\beta(T, m)=\beta_{\mathrm{s}}^{\mathrm{E}} \beta^{*}+\beta_{\mathrm{w}}(T)$

$\beta_{\mathrm{w}}=\sum_{i=0}^{4} \beta_{i} \cdot T^{i}$

$\beta_{\mathrm{s}}^{\mathrm{E}}=\gamma_{0}+\gamma_{1} \cdot T-\beta_{\mathrm{w}}$

$m_{\mathrm{s}}=\sum_{i=0}^{2} m_{i} \cdot T^{i}$

$\beta^{*}=\sum_{i=1}^{2} \beta_{i}^{*} \cdot C_{\mathrm{m}}^{i}$

The constants in above equations are given in Table 8. Brine dynamic viscosity can now be computed using Eq. (31).

$\mu\left(p, T, C_{\mathrm{m}}\right)=\mu^{0}\left(T, C_{\mathrm{m}}\right)\left[1+\beta\left(C_{\mathrm{m}}, m\right) p\right]$

In this equation, $T$ is the temperature in ${ }^{\circ} \mathrm{C}$ and $\mu$ is brine dynamic viscosity in $\mathrm{kg} / \mathrm{m} \mathrm{s}$.

\section{References}

Andersen P, Evje S, Madland MV, Hiorth A (2012) A geochemical model for interpretation of chalk core flooding experiments. Chem Eng Sci 84:218-241

Atthawutthisin N (2012) Numerical simulation of low salinity water flooding assisted with chemical flooding for enhanced oil recovery. Institutt for petroleumsteknologi og anvendt geofysikk, Norwegian University of Science and Technology (NTNU)
Austad T, Strand S, Høgnesen E, Zhang P (2005) Seawater as IOR fluid in fractured chalk. In: SPE international symposium on oilfield chemistry, 2005. Society of Petroleum Engineers

Austad T, Strand S, Madland MV, Puntervold T, Korsnes RI (2007) Seawater in chalk: an EOR and compaction fluid. In: International petroleum technology conference, 2007

Austad T, RezaeiDoust A, Puntervold T (2010) Chemical mechanism of low salinity water flooding in sandstone reservoirs. In: SPE improved oil recovery symposium, 2010. Society of Petroleum Engineers

Austad T, Shariatpanahi S, Strand S, Black C, Webb K (2011) Conditions for a low-salinity enhanced oil recovery (EOR) effect in carbonate oil reservoirs. Energy Fuels 26:569-575

Bader M (2007) Seawater versus produced water in oil-fields water injection operations. Desalination 208:159-168

Bartels W-B, Mahani H, Berg S, Hassanizadeh SM (2019) Literature review of low salinity waterflooding from a length and time scale perspective. Fuel 236:338-353

Berg S, Cense A, Jansen E, Bakker K (2010) Direct experimental evidence of wettability modification by low salinity. Petrophysics 51:05

Bernard GG (1967) Effect of floodwater salinity on recovery of oil from cores containing clays. In: SPE California regional meeting, Los Angeles, 26-27 October 1967. Society of Petroleum Engineers

Brady PV, Krumhansl JL, Mariner PE (2012) Surface complexation modeling for improved oil recovery. In: SPE improved oil recovery symposium society of petroleum engineers

Craig FF (1971) The reservoir engineering aspects of waterflooding, vol 3. HL Doherty Memorial Fund of AIME, New York

Dang CTQ, Nghiem LX, Chen ZJ, Nguyen QP (2013) Modeling low salinity waterflooding: ion exchange, geochemistry and wettability alteration. In: SPE Annual technical conference and exhibition, New Orleans, 30 September-2 October 2013. Society of Petroleum Engineers

Delshad M, Najafabadi NF, Anderson G, Pope GA, Sepehrnoori K (2009) Modeling wettability alteration by surfactants in naturally fractured reservoirs. SPE Reserv Eval Eng 12:361-370

Ertekin T, Abou-Kassem JH, King GR (2001) Basic applied reservoir simulation, vol 7. Society of Petroleum Engineers, Richardson

Esmaeili S, Rahbar M, Pahlavanzadeh H, Ayatollahi S (2016) Investigation of streaming potential coupling coefficients and zeta potential at low and high salinity conditions: experimental and modeling approaches. J Petrol Sci Eng 145:137-147

Fathi SJ, Austad T, Strand S (2010) "Smart water" as a wettability modifier in chalk: the effect of salinity and ionic composition. Energy Fuels 24:2514-2519

Gibson R, Loeffler O (1941) Pressure-volume-temperature relations in solutions. IV. The apparent volumes and thermal expansibilities of sodium chloride and sodium bromide in aqueous solutions between 25 and $95^{\circ}$. J Am Chem Soc 63:443-449

Hilbert R (1979) PVT-daten von Wasser und von wässrigen Natriumchlorid-lösungen bis $873 \mathrm{~K}, 4000 \mathrm{Bar}$ und 25 Gewichtsprozent $\mathrm{NaCl}$. Hochschulverlag, Zurich

Hilner E, Andersson MP, Hassenkam T, Matthiesen J, Salino P, Stipp SLS (2015) The effect of ionic strength on oil adhesion in sandstone-the search for the low salinity mechanism. Sci Rep 5:9933

Hognesen EJ, Strand S, Austad T (2005) Waterflooding of preferential oil-wet carbonates: oil recovery related to reservoir temperature and brine composition. In: SPE Europec/EAGE annual conference society of petroleum engineers

Jadhunandan P, Morrow NR (1995) Effect of wettability on waterflood recovery for crude-oil/brine/rock systems. SPE Reserv Eng 10:40-46 
Jerauld G, Lin C, Webb K, Seccombe J (2006a) Modeling LowSalinity Waterflooding. In: SPE annual technical conference and exhibition, San Antonio, 24-27 September

Jerauld GR, Webb KJ, Lin C-Y, Seccombe J (2006b) Modeling lowsalinity waterflooding. In: spe annual technical conference and exhibition society of petroleum engineers

Jerauld GR, Webb KJ, Lin C-Y, Seccombe JC (2008) Modeling lowsalinity waterflooding. SPE Reserv Eval Eng 11:1000-1012

Kestin J, Khalifa HE, Correia RJ (1981) Tables of the dynamic and kinematic viscosity of aqueous $\mathrm{NaCl}$ solutions in the temperature range 20-150 C and the pressure range 0.1-35 MPa. J Phys Chem Ref Data 10:71-88

Kim C, Lee J (2017) Experimental study on the variation of relative permeability due to clay minerals in low salinity water-flooding. J Petrol Sci Eng 151:292-304

Lager A, Webb K, Black C, Singleton M, Sorbie K (2008a) Low salinity oil recovery-an experimental investigation. Petrophysics 49:28-35

Lager A, Webb KJ, Collins IR, Richmond DM (2008b) LoSal enhanced oil recovery: Evidence of enhanced oil recovery at the reservoir scale. In: SPE symposium on improved oil recovery, Tulsa, 20-23 April. Society of Petroleum Engineers

Mahani H, Sorop T, Ligthelm DJ, Brooks D, Vledder P, Mozahem F, Ali Y (2011) Analysis of field responses to low-salinity waterflooding in secondary and tertiary mode in Syria. In: SPE EUROPEC/EAGE annual conference and exhibition, Vienna, 23-26 May. Society of Petroleum Engineers

McGuire P, Chatham J, Paskvan F, Sommer D, Carini F (2005) Low salinity oil recovery: an exciting new EOR opportunity for Alaska's North Slope. In: SPE Western regional meeting, Irvine, 30 March-1 April 2005. Society of Petroleum Engineers

Mohamed I, He J, Nasr-El-Din HA (2013) Effect of brine composition on $\mathrm{CO}_{2} /$ limestone rock interactions during $\mathrm{CO}_{2}$ sequestration. $\mathrm{J}$ Pet Sci Res 2:14-26

Morrow NR, Tang G-q, Valat M, Xie X (1998) Prospects of improved oil recovery related to wettability and brine composition. J Petrol Sci Eng 20:267-276

Myint PC, Firoozabadi A (2015) Thin liquid films in improved oil recovery from low-salinity brine. Curr Opin Colloid Interface Sci 20:105-114

Nasralla RA, Nasr-El-Din HA (2014) Double-layer expansion: is it a primary mechanism of improved oil recovery by low-salinity waterflooding? SPE Reserv Eval Eng 17:49-59

Nasralla RA et al (2014) Demonstrating the potential of low-salinity waterflood to improve oil recovery in carbonate reservoirs by qualitative coreflood. In: Abu Dhabi international petroleum exhibition and conference, society of petroleum engineers

Omekeh AV, Evje S, Friis HA (2012) Modeling of low salinity effects in sandstone oil rocks. Int J Numer Anal Model 1:1-18

Omekeh AV, Evje S, Friis HA (2013) Modeling of low salinity effects in sandstone oil rocks. Int J Numer Anal Model Ser B 4:95-128

Osif TL (1988) The effects of salt, gas, temperature, and pressure on the compressibility of water. SPE Reserv Eng 3:175-181

Puntervold T, Strand S, Austad T (2007) New method to prepare outcrop chalk cores for wettability and oil recovery studies at low initial water saturation. Energy Fuels 21:3425-3430

Purswani P, Tawfik MS, Karpyn ZT (2017) Factors and mechanisms governing wettability alteration by chemically tuned waterflooding. A review. Energy Fuels 31:7734-7745

Qiao C, Li L, Johns RT, Xu J (2014) A mechanistic model for wettability alteration by chemically tuned water flooding in carbonate reservoirs. In: SPE annual technical conference and exhibition Society of Petroleum Engineers

Qiao C, Johns R, Li L (2016) Modeling low-salinity waterflooding in chalk and limestone reservoirs. Energy Fuels 30:884-895
Rahbar M, Jafarlou A, Nejadali M, Esmaeili S, Pahlavanzadeh H, Ayatollahi S (2017) Streaming Potential measurement to quantify wetting state of rocks for water based EOR, in-house novel setup experience. In: IOR 2017-19th European symposium on improved oil recovery

Reiter PK (1961) A water-sensitive sandstone flood using low salinity water. University of Oklahoma, Oklahoma

Rowe AM Jr, Chou JC (1970) Pressure-volume-temperature-concentration relation of aqueous sodium chloride solutions. J Chem Eng Data 15:61-66

Shariatpanahi SF, Strand S, Austad T (2010) Evaluation of waterbased enhanced oil recovery (EOR) by wettability alteration in a low-permeable fractured limestone oil reservoir. Energy Fuels 24:5997-6008

Shojaei M-J, Ghazanfari MH, Masihi M (2015) Relative permeability and capillary pressure curves for low salinity water flooding in sandstone rocks. J Nat Gas Sci Eng 25:30-38

Skrettingland K, Holt T, Tweheyo MT, Skjevrak I (2011) Snorre lowsalinity-water injection-coreflooding experiments and single-well field Pilot. SPE Reserv Eval Eng 14:182-192

Spivey J, McCain W Jr, North R (2004) Estimating density, formation volume factor, compressibility, methane solubility, and viscosity for oilfield brines at temperatures from 0 to $275 \mathrm{C}$, pressures to $200 \mathrm{MPa}$, and salinities to $5.7 \mathrm{~mole} / \mathrm{kg}$. J Can Pet Technol 43:52-61

Strand S, Austad T, Puntervold T, Høgnesen EJ, Olsen M, Barstad SMF (2008) "Smart water" for oil recovery from fractured limestone: a preliminary study. Energy Fuels 22:3126-3133

Takahashi S, Kovscek AR (2010) Wettability estimation of low-permeability, siliceous shale using surface forces. J Petrol Sci Eng 75:33-43

Tang G, Morrow NR (1997) Salinity, temperature, oil composition, and oil recovery by waterflooding. SPE Reserv Eng 12:269-276

Tang G-Q, Morrow NR (1999) Influence of brine composition and fines migration on crude oil/brine/rock interactions and oil recovery. $\mathbf{J}$ Petrol Sci Eng 24:99-111

Tiab D, Donaldson EC (2015) Petrophysics: theory and practice of measuring reservoir rock and fluid transport properties. Gulf Professional, Houston

Vinogradov J, Jaafar MZ, Jackson MD (2010) Measurement of streamingpotential coupling coefficient in sandstones saturated with natural and artificial brines at high salinity. J Geophys Res 115:B12204. https://doi.org/10.1029/2010JB007593

Webb K, Black C, Al-Ajeel H (2003) Low salinity oil recovery-loginject-log. In: Middle East oil show, Bahrain, 9-12 Jun 2003. Society of Petroleum Engineers

Webb K, Black C, Edmonds I (2005a) Low salinity oil recovery-the role of reservoir condition corefloods. In: 13th European symposium on improved oil recovery, Budapest, 25-27 April

Webb KJ, Black CJJ, Tjetland G (2005b) A laboratory study investigating methods for improving oil recovery in carbonates. In: International petroleum technology conference

Webb K, Lager A, Black C (2008) Comparison of high/low salinity water/oil relative permeability. In: International symposium of the society of core analysts, Abu Dhabi, UAE, Abu Dhabi, 29 October-2 November 2008

Yildiz HO, Morrow NR (1996) Effect of brine composition on recovery of Moutray crude oil by waterflooding. J Petrol Sci Eng 14:159-168

Yousef AA, Al-Saleh SH, Al-Kaabi A, Al-Jawfi MS (2011) Laboratory investigation of the impact of injection-water salinity and ionic content on oil recovery from carbonate reservoirs. SPE Reserv Eval Eng 14:578-593

Yu L, Evje S, Kleppe H, Kårstad T, Fjelde I, Skjaeveland S (2009) Spontaneous imbibition of seawater into preferentially oil-wet 
chalk cores-experiments and simulations. J Petrol Sci Eng 66:171-179

Zeinijahromi A, Ahmetgareev V, Badalyan A, Khisamov R, Bedrikovetsky P (2015) Case study of low salinity water injection in zichebashskoe field. J Pet Sci Res 4:16-31

Zhang Y, Morrow NR (2006) Comparison of secondary and tertiary recovery with change in injection brine composition for crude-oil/ sandstone combinations. In: SPE/DOE symposium on improved oil recovery, Tulsa, 22-26 April 2006. Society of petroleum engineers

Zhang P, Tweheyo MT, Austad T (2006) Wettability alteration and improved oil recovery in chalk: the effect of calcium in the presence of sulfate. Energy Fuels 20:2056-2062
Zhang Y, Xie X, Morrow NR (2007a) Waterflood performance by injection of brine with different salinity for reservoir cores. In: SPE annual technical conference and exhibition society of petroleum engineers

Zhang P, Tweheyo MT, Austad T (2007b) Wettability alteration and improved oil recovery by spontaneous imbibition of seawater into chalk: impact of the potential determining ions $\mathrm{Ca}^{2+}, \mathrm{Mg}^{2+}$, and SO42. Colloids Surf Physicochem Eng Aspects 301:199-208

Publisher's Note Springer Nature remains neutral with regard to jurisdictional claims in published maps and institutional affiliations 